Series 07 Aerospace Materials 09

The Significance of Fractography for Investigations of Fatigue Crack Growth under Variable-Amplitude Loading

J. Schijve

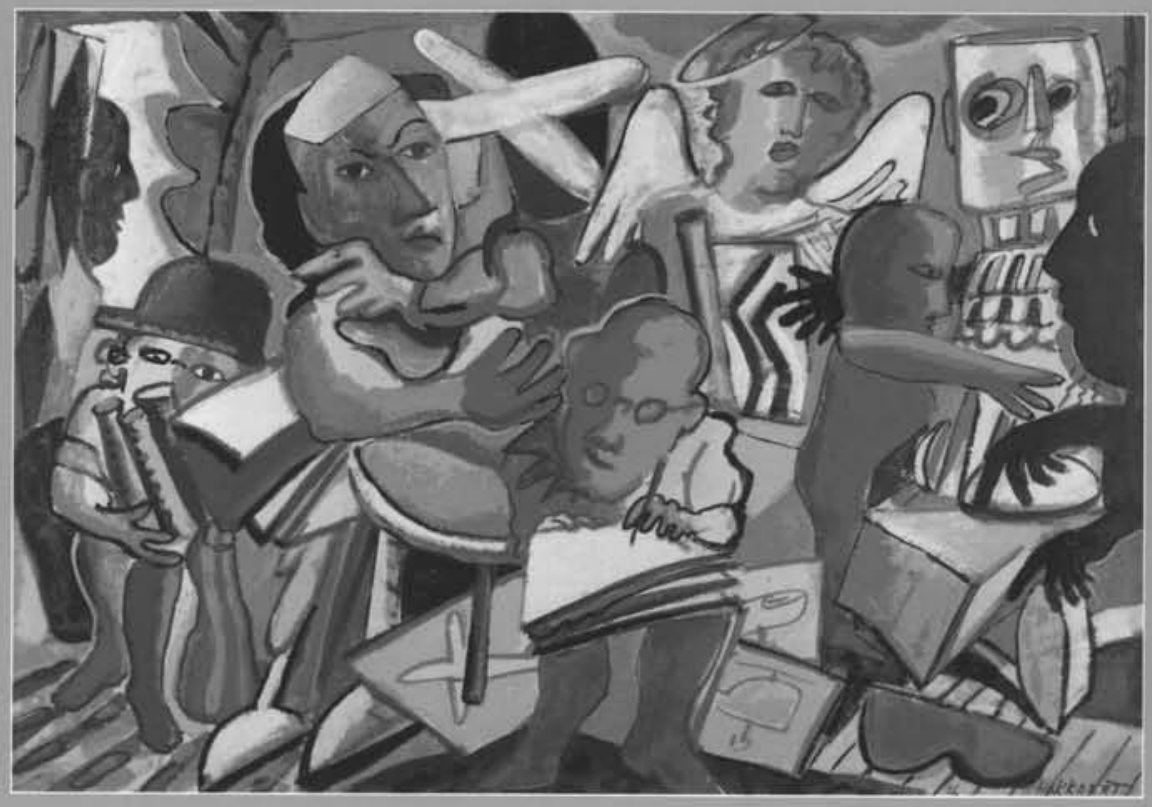

Delft University Press 
The Significance of Fractography for Investigations of Fatigue Crack Growth under Variable-Amplitude Loading

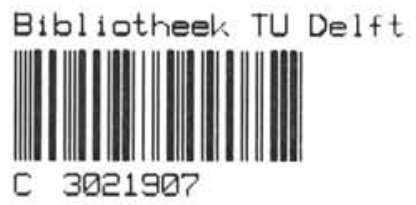


Series 07: Aerospace Materials 09 


\section{The Significance of Fractography for Investigations of Fatigue Crack Growth under Variable-Amplitude Loading}

J. Schijve

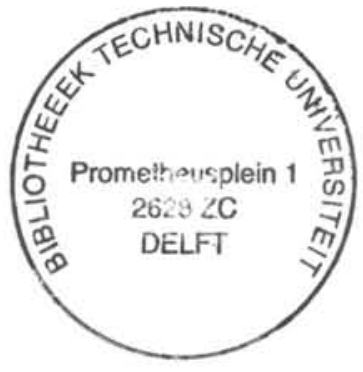

Delft University Press / 1998 
Published and distributed by:

Delft University Press

Mekelweg 4

2628 CD Delft

The Netherlands

Telephone +31 (0) 152783254

Fax +31 (0) 152781661

e-mail: DUP@DUP.TUDelft.NL

by order of:

Faculty of Aerospace Engineering

Delft University of Technology

Kluyverweg 1

P.O. Box 5058

2600 GB Delft

The Netherlands

Telephone +31 (0) 152781455

Fax + 31 (0)15 2781822

e-mail: Secretariaat@LR.TUDelft.NL

website: http://www.Ir.tudelft.nl/

Cover: Aerospace Design Studio, $66.5 \times 45.5 \mathrm{~cm}$, by:

Fer Hakkaart, Dullenbakkersteeg 3, 2312 HP Leiden, The Netherlands

Tel. + 31 (0) 715126725

$90-407-1716-8$

Copyright ${ }^{\oplus} 1998$ by Faculty of Aerospace Engineering

All rights reserved.

No part of the material protected by this copyright notice may be reproduced or utilized in any form or by any means, electronic or mechanical, including photocopying, recording or by any information storage and retrieval system, without written permission from the publisher: Delft University Press.

Printed in The Netherlands 


\begin{abstract}
Fatigue crack growth tests were carried out on 2024-T3 and 7075-T6 central cracked specimens. Variable-amplitude (VA) load spectra were used with periodic overload (OL) cycles added to constant-amplitude (CA) cycles. The fatigue fracture surfaces were examined in the SEM to obtain more detailed information on crack growth contributions of different load cycles. The striation patterns could be related to the load histories. SEM observations were associated with delayed retardation, the effect of 10 or a single OL on retardation, crack growth during the OL cycles, and crack growth arrest after a high peak load. Fractographs exhibited local scatter of crack growth rates and sometimes a rather tortuous $3 \mathrm{~d}$ geometry of the crack front. Indications of structural sensitive crack grwoth under VA loading were obtained. Fractography appears to be inadmissable for the evaluation of fatigue crack growth prediction models in view of similarities and dissimilarities between crack growth and VA and CA loading.
\end{abstract}

\title{
Nomenclature
}

$\begin{array}{ll}\text { a } & \text { crack length } \\ \text { BL cycles } & \text { base line cycles } \\ \text { CA-loading } & \text { constant-amplitude loading } \\ \text { da/dN } & \text { crack growth rate } \\ \text { OL cycles } & \text { overload cycle } \\ \text { VA loading } & \text { variable-amplitude cycles } \\ \Delta \mathrm{K}_{\text {eff }} & \text { effective stress intensity factor } \\ \Delta \mathrm{S}_{\text {eff }} & \text { effective stress range }\end{array}$

\section{Introduction}

The problem addressed in this paper is the potential usefulness of fractographic evidence to analyze prediction problems of fatigue crack growth under variable-amplitude (VA) loading. Verifications of prediction models can be made on different levels. The most global one is a comparison of predicted and experimental crack growth lives. If they do agree, it is possible that an underprediction in the first part of the crack growth life is compensated by an overestimation in the second part. In other words, in the first part the crack growth rate $d a / d N$ is overestimated, whereas $d a / d N$ is underestimated in the second part. The prediction model is apparently not accurate. 
A more precise verification of a prediction model requires that the crack growth rate is correctly predicted for the entire crack growth life. Such verifications are made by comparing predicted and experimental $d a / d N$ values as a function of the crack length $a$. If the predicted relation and the experimental one are similar, the prediction model could be supposed to be accurate. However, $d a / d N$ values as obtained from crack growth records are calculated slopes. Such $d a / d N$ values still have a kind of a global nature. Fig.1 shows the load spectra applied in the present test series. The spectra contain small base line (BL) cycles and intermittent larger overload (OL) cycles. If the crack rate during the large cycles is higher than predicted by a cycleby-cycle prediction model, and the crack rate during the small cycles is lower than predicted, then the predicted growth rate per spectrum block can still agree with the experimental value. Local under-predictions can be canceled by local over-predictions. The prediction model might appear to be acceptable, but it is physically still not correct. Prediction models should be verified by still more detailed crack growth measurements. Ultimately, the crack rate should be measured in each individual cycle. Experimentally it implies that striation spacings have to be measured. Fractographic observations in the electron microscope are essential for that purpose.

Experiments were carried out on 2024-T3 (bare) and 7075-T6 (clad) specimens with simple VA load histories (Fig.1). Simple load spectra were chosen to be sure about striation patterns which might be visible in the scanning electron microscope (SEM). The experimental conditions and load histories are described first, followed by results, a discussion and some conclusions. It is not the the aim as yet to compare the observations with results of a prediction model.

\section{Experimental conditions}

Crack growth fatigue tests were carried out in an electro-hydraulic fatigue machine equipped with MTS TestStar computer controlled load monitoring. The tests occurred in normal lab air. Central cracked tension specimens were used, see Fig.2. The specimens were produced from $4 \mathrm{~mm}$ thick plates. A lower thickness might have given shear lips in a too early stage of the crack growth. Plates of 2024-T3 bare and 7075-T6 Clad material were used as they were available 
in stock. Moreover, it could be expected that the two alloys would show striations in the SEM. Static properties $\mathrm{S}_{\mathrm{U}}, \mathrm{S}_{0.2}$ and elongation are $469 \mathrm{MPa}, 324 \mathrm{MPA}$ and $20 \%$ for the 2024 alloy, and $510 \mathrm{MPa}, 550 \mathrm{MPa}$ and $12 \%$ for the 7075 alloy.

The specimens were cut from a plate, without any special sheet surface treatment. The crack starter notch consists of a $3 \mathrm{~mm}$ hole with two hand made saw cuts at the two hole edges, leading to a crack starter notch tip to tip of $10 \mathrm{~mm}$ (a single exception with tip to tip $20 \mathrm{~mm}$ ).

In view of the purpose of the experiments a simple crack length measurement technique was adopted. A paper millimeter scale was attached to the specimen, see Fig.2. The crack tips were observed through a binocular microscope with a low magnification (16x) at somewhat arbitrarily selected intervals.

\section{Load histories}

Five different load histories were used, see Fig.1. The load histories are repeated until failure. Numeric information is summarized in Table 1. All load spectra consist of small base line (BL) cycles and intermediate larger overload (OL) cycles. Spectra 1 to 4 were applied to specimens of both alloys. Spectrum 5 was applied to the 2024-T3 alloy only.

\begin{tabular}{|c|c|c|c|c|c|c|}
\hline Spectrum & Cycles per spectrum period & \multirow{2}{*}{ Total } & \multicolumn{3}{|c|}{ Stress levels (MPA) } \\
\cline { 4 - 7 } & & & number & \multicolumn{2}{|c|}{ OL's } & \multicolumn{2}{c|}{ BL cycles } \\
\cline { 4 - 7 } & & & $\max$ & $\min$ & $\max$ & $\min$ \\
\hline 1 & $10+100+1+100$ & 211 & 100 & 5 & 80 & 5 \\
\hline 2 & $10+20+10+50+10+100+10+200$ & 410 & 100 & 5 & 80 & 5 \\
\hline 3 & $10+200+1+200$ & 411 & 90 & 5 & 65 & 5 \\
\hline 4 & $10+100+5+100+5+100+10+100$ & 430 & 100 & 2 & 80 & 20 \\
\hline 5 & $10+2006+1+2006$ & 4013 & 90 & 5 & 65 & 5 \\
\hline CA & & & & & 65 & 5 \\
\hline
\end{tabular}

Table 1: Summary of spectrum characteristics.

In spectrum 1 a block of $10 \mathrm{OL}$ cycles and a single OL cycle were applied alternately. The main purpose was to see whether the crack extension in the $100 \mathrm{CA}$ cycles would be different after a block of $10 \mathrm{OL}$ cycles and a single OL cycle. Spectrum 3 is a variant of spectrum 1 with different 
stress levels and twice as much BL cycles between the OL applications. The OL cycles of spectrum 3 are relatively more severe, $\Delta S_{O L} / \Delta S_{B L}$ is 1.42 for spectrum 3, whereas it is 1.27 for spectrum 1. Spectrum 5 is similar to spectrum 3, but the number of BL cycles between OLs is about 10 times larger. Actually, spectrum 5 was used to examine the possibility of a full reconstruction of the crack growth curve from fractographic observations.

In spectrum 2 all OL blocks are the same, but the number of cycles in the CA blocks are different. The fractographic band width of blocks of the BL cycles could then give an indication on delayed retardation.

In spectrum 4 the most significant variable is the transition from the OL cycles to the $\mathrm{CA}$ cycles and vice versa. It can be done from a maximum of the OL blocks to the minimum of the CA block, but it can also be done from the minimum of the $\mathrm{OL}$ cycle to the maximum of the $\mathrm{CA}$ block. Crack closure based prediction models suggest different sequence effects depending on the transition. Indication on this issue could be obtained from the fractographic band width of the 100 base line cycles. Two different numbers of OL cycles ( 5 and 10) were applied in order to recognize the correspondence of the striation bands with the location in the load spectrum.

Constant-amplitude (CA) tests were carried out as a reference to see whether crack growth retardation occurred.

\section{Crack growth records}

A full tabular and graphical compilation of all test results is given in a separate document [1]. Selected graphs of the experimental results are presented here to illustrate the crack growth behaviour of the two alloys as tested under the five load spectra.

Fig. 3 shows the results of both alloys for spectrum 4 . The crack growth life for the 2024T3 bare specimen is significantly longer than for the 7075-T6 clad material. Crack growth life ratios (2024/7075) for spectra 1 to 4 are 1.8, 2.3, 2.8 and 2.5 respectively. These values are quite normal, also keeping in mind that 2024 was in the bare condition, whereas the 7075 sheet was clad material. Similar graphs as shown in Figs.3a and $3 \mathrm{~b}$ for the other spectra are given in [1].

The results of all experiments, including the CA tests, are presented in Figs.4a and $4 \mathrm{~b}$ for the two aluminium alloys respectively. The crack growth rates were calculated from the crack growth 
records as:

$$
\frac{d a}{d N}=\frac{a_{i}-a_{l}}{N_{i}-N_{l}}
$$

These values are plotted as a function of $\Delta K_{\text {eff }}$ for the BL cycles:

$$
\Delta K_{\text {eff }}=C \Delta S_{\text {eff }} \sqrt{\pi a} \text { with } \quad C=\sqrt{\cos \left(\frac{\pi a}{W}\right)}
$$

The value of $\Delta S_{\text {eff }}$ is calculated for $\Delta S$ of the BL cycles.

The comparison in Fig. 4 on the basis of an effective $\Delta K$ was necessary because the stress levels and the stress ratios $\mathrm{R}$ were different for several spectra. The effective values were obtained by using the equation:

$$
U=\frac{\Delta S_{\text {eff }}}{\Delta S}=0.55+0.33 R+0.12 R^{2}
$$

which which has given a good correlation for different stress ratios $\mathrm{R}$ [2].

As shown by the results in Fig. 4 the highest crack growth rates were obtained with the CA loading. It implies that in all other tests crack growth retardations occurred. However, the retardation was relatively small for most spectra, except for spectrum 3 which obviously resulted in a significant retardation. This is more clear from Fig. 5 where the crack rate for spectra 3 and 5 and for the CA tests are shown as a function of crack length. For these three loading cases the BL cycles occurred at the same cyclic stress, which allows a comparison of crack rates as a function of the crack length. On the average, crack rates for 2024-T3 under spectrum 3 were about 3.5 times lower than in the CA test. A similar factor for 7075-T6 was about 2.3. The crack rates for spectrum 5 (measured for 2024-T3 only) were lower than in the CA test, but that was in the order of about 1.4 times, much less than for spectrum 3. This smaller retardation should be associated with the 10 times larger number of BL cycles between the OLs of spectrum 5 . 


\section{Fractography}

The fatigue crack surfaces as examined by the naked eye show a relatively flat fracture surface, which is characteristic for fatigue. Initially the fracture surface was perpendicular to the loading direction, see Fig.6. In this tensile mode part of the fatigue fracture, the fracture surface was more flat for the 2024-T3 specimens as compared to the fracture surfaces of the 7075-T6 specimens. For an increasing crack length the shear lips became broader, and when the shear lips covered the full specimen thickness, it usually led to a single shear crack. A double shear crack was occasionally observed. The final failure occurred in the shear mode.

\section{Macro-bands}

Macro-bands could be observed with the unaided eye, see Fig.6. With a small magnifying glass ( $8 \mathrm{x})$ and incident rays from a suitable direction many more bands were visible on specimens tested under spectrum 3 and 4 . The bands could be seen for larger cracks only. The bands were sharper lines and could be more easily seen on the 7075-T6 specimens. For the 2024-T3 specimens significant shear lips had already developed when the bands were observed.

The bands in the spectrum 3 tests correspond to the blocks of $10 \mathrm{OL}$ cycles, while extremely faint lines could sometimes be observed for the single OL cycle. For spectrum 4, the bands were associated with the blocks of 5 or $10 \mathrm{OL}$ cycles. The band spacing was measured by counting the number of bands in intervals of $1 \mathrm{~mm}$. The counting results were used for calculating the crack rate $d a / d N$. Because of the observation technique with a manually operated magnifying glass the results do not have a high accuracy. Tabular results are collected in [1]. Results of spectrum 4 are presented here in Fig.3b. The agreement with the crack growth records is good as should be expected.

\section{Crack rates derived from SEM pictures}

Samples were cut from the specimen, see Fig.2, for examination in the scanning electron microscope (SEM). The fracture surfaces were cleaned and gold sputtered. The samples were then mounted in the SEM (Jeol JSM-840A), which was equipped with a SEMafore, a digital image recording and processing system. It allows in situ measurements of distances between selected 
points of the fracture surface. Local crack rates were obtained by measuring the distance between a number of bands of OL blocks as shown in Fig.7a. In this figure 18 spacings between the bands of 10 OL cycles covered a distance of $90.3 \mu \mathrm{m}$ measured in the SEM, corrected for a tilting angle of $35^{\circ}$. With 211 cycles per spectrum period the local crack growth rate is then found to be 90.3 $/ 18 / 211=0.024 \mu \mathrm{m} / \mathrm{c}$. Tilting was done to improve the visibility of the striations. The location of the measurement was also determined in the SEM, either by using the $\mathrm{X}, \mathrm{Y}$ reading system of the microscope, or by measuring in the SEM the distance to the tip of the saw cut. Crack rate values were obtained in this way for 3 to 6 crack lengths per specimen. The results are collected in tabular format in [1]. Results for spectrum 2 are presented here in Fig.3b. The agreement with the results of the crack growth records was generally good. Both small positive and negative differences were found.

It still should be recognized that the fractography has revealed local scatter of the crack rate, see as an example Fig.7a. Moreover, the crack front is not a straight line, actually it is a quite tortuous line, and some dispersion of the crack rate along the crack front must be expected. As a consequence, the result of measurements are depending on the location of the measurements. Although striations of the OL cycles were observed rather abundantly, the pattern could sometimes be rather erratic, the more so for the 7075-T6 alloy. An example of an erratic picture is given in Fig.8, although it still allows a determination of the local crack rate. However, in such cases due attention must be focused on the fractographic examination. Both experience and knowledge of the pictures to be expected are then important.

\section{Results of spectra 1.3 and 5}

More detailed information on crack growth rates is obtained by measuring the band width $(\Delta a)$ of separate cycle blocks. Fig.7b illustrates which dimensions have been measured in the SEM for this purpose. It is of some interest to see whether $\Delta \mathrm{a}$ in $100 \mathrm{BL}$ cycles after an OL block of 10 cycles $\left(\Delta a_{l}\right.$ in Fig.7) differs from $\Delta \mathrm{a}$ in $100 \mathrm{BL}$ cycles after a single OL cycle $\left(\Delta a_{2}\right.$ in Fig.7b). Such measurements were made for spectrum 1 (100 BL cycles in a single BL block) and spectrum 3 (200 BL cycles in a single BL block). For the 7075-T6 specimens not enough accurate measurements could be made because of less clearly defined striations of the OL cycles. Results for the 2024-T3 are presented in the table below. 


\begin{tabular}{|c|c|c|c|c|c|}
\hline spectrum & $a(\mathrm{~mm})$ & \multicolumn{3}{|c|}{$\Delta a_{I} / \Delta a_{2}$} & average ratio \\
\hline 1 & 9.1 & 0.98 & 0.92 & 0.97 & \\
& 14.0 & 1.15 & 1.05 & & 1.05 \\
& 17.6 & 1.14 & 1.24 & 0.94 & \\
\hline 2 & 15.1 & 1.27 & 1.01 & 0.89 & \\
& 20.0 & 0.97 & & & 1.00 \\
& 24.6 & 0.96 & 0.96 & 0.95 & \\
\hline
\end{tabular}

Table 2: Ratios of crack increments in two base line blocks.

Although there is some scatter in the results the general trend appears to be that a systematic difference between $\Delta a_{1}$ and $\Delta a_{2}$ has not been observed.

Similar SEM measurements could not be made on the 2024-T3 specimen tested under spectrum 5 because of the much larger BL blocks (2006 cycles in each block). However, the crack growth curve of this specimen could be reconstructed from the SEM observations. X-values of the microscope were read at all successive bands of 10 and a single OL cycle of spectrum 5 . A picture of a striation of a single OL is shown in Fig.9a. The crack length values thus obtained are plotted in Fig.9b, which shows a very good agreement with the visually obtained crack growth curve. It indicates that none of the OL bands was missed, an essential requirement for reconstructing a crack growth curve from fractographic data. At the upper end of the crack growth curve the SEM data continue beyond the visual crack growth data. The last two visual data deviate from the SEM data. The SEM results are considered to be more reliable in this case.

The OL striation in Fig.9a confirms again that the crack front is not a straight line. Since the bands had a spacing in the order of $500 \mu \mathrm{m}$ it is easy to understand that a careful examination of the fracture is essential for not missing any of the bands. In this respect it was helpful that the number of cycles in the OL blocks was alternating between 1 and 10 . Although 10 striations of a block of 10 OL cycles were usually not separately visible, those bands were broader than for a single OL cycle. The alternating band width thus helps in not missing a single OL application. The SEM results of specimen 2024-5 did not reveal any systematic difference between the crack growth rates in the two BL blocks of the spectrum, in agreement with the results in table 2. 


\section{Results of spectrum 2}

The fracture surfaces of specimens tested with spectra 2 can offer interesting information on crack length increments $(\Delta a)$ occurring during the blocks with $\mathrm{BS}$ line cycles. The question is whether the same $d a / d N$ is observed for the blocks with $20,50,100$ and 200 cycles respectively. The width of the base line blocks should then be proportional to the number of cycles in a block. If this is not true, it indicates some transient crack growth retardation effect.

Fractographic pictures of specimen 2024-2 loaded with spectrum 2 are presented in Figs.10a and $10 \mathrm{~b}$. The bands of the blocks with $10 \mathrm{OL}$ cycles are clearly visible. The intermediate areas of the BL cycles in Fig.10b vaguely suggest indications of striations of these cycles, but that is not correct as could be shown by larger magnifications. The band width $(\Delta a)$ of the BL cycles was measured with the SEMafore as described previously for Fig. $7 \mathrm{~b}$. The $\Delta$ a-values were used to calculate the average crack growth rate in these bands. The numerical results, compiled in [1], are presented here in Fig.11. Apparently the average crack growth rate in the four bands with different $\mathrm{BL}$ cycles decreases for an increasing number of BL cycles of the band. The results do not look fully systematic, which may be due to a limited accuracy of the measurements and local scatter of the crack rate in the material. In spite of this, the trend of a decreasing average $d a / d N$ for an increasing $\Delta N$ of the bands seems to be obvious. It indicates a delayed retardation.

\section{Results of spectrum 4}

For spectrum 4 the question is whether the crack growth rate in the base line blocks $\mathrm{A}$ and B (Fig.1) are the same. Then $\Delta a$ in these blocks should be the same. If this is not true, it indicates some effect of the transition from OL cycles to BL cycles.

SEM pictures of fractographs of specimens of the two alloys are shown in Figs.12a and $12 \mathrm{~b}$ respectively. The question is whether the BL blocks A and B (see Fig.1) would give the same or systematically different crack growth increments $\Delta a$. In both Figs.12a and $12 \mathrm{~b}$ the blocks with OL cycles are clearly visible. But there is a difference between the two aluminium alloys. The 2024 specimen clearly shows either 10 or 5 striations for all OL cycles. That is not true for the 7075 specimen, although the bands of the OL blocks can easily be observed. Measurements for each alloy were made in two micrographs with 5 to 8 bands in each micrograph. The results did not indicate a systematic difference between the crack rates in BL blocks A and B. 


\section{Delaved retardation indicated by $B L$ cycle striations}

In generally striations of the BL cycles were hard to detect. Occasionally areas were found where these striations could be reliably identified. An example for 2024-T3 is given in Fig.13a. In this picture 100 striations of the $100 \mathrm{BL}$ cycles can be counted between the OL applications. The striations directly after the $10 \mathrm{OL}$ cycles (area A in Fig.13a) show a wider spacing than later striations (area B in Fig.13a). That indicates delayed retardation. Similarly in Fig.13b for a 7075 specimen, the striations in area B directly after the preceding OL cycles (area A) also show a wider spacing than later striations in area $\mathrm{C}$. The lines to be seen in area $\mathrm{D}$ are labeled as quasi striations. These lines are not really striations in the sense of one striation per cycle. This problem was previously recognized in $[3,4,4 a]$.

Two SEM pictures were used for a more elaborate analysis. In order to maintain a reasonable accuracy, crack growth increments corresponding to 10 cycles were measured on these pictures. The average $d a / d N$ of these groups of 10 cycles are plotted in Figs.14a and b. Both graphs confirm the delayed retardation.

\section{Crack growth rates in the blocks of $100 \mathrm{OL}$ cycles}

Micrographs as shown in Figs.7b, 10b and 12a can be used to measure the band width of the $10 \mathrm{OL}$ cycle striations. This has been done for the most suitable micrographs. The results for 2024-T3 are shown in Fig.15. Each data point is the average of 2 to 5 bands in the same micrograph. The results are compared to the crack growth rate observed in the CA test. Deviations do occur, but measurement inaccuracies and the fact, that only one CA test was carried out, can contribute to discrepancies. There is no obvious trend for an increased crack growth rate in the OL cycles if compared to the growth rates under CA loading. The two data points at the highest $\Delta K_{\text {eff }}$ are considerably below the CA results. It should be noted that the fracture surface of the CA specimen at these high $\Delta K_{e f f}$ values was fully in the shear mode, whereas the spectrum specimens were still partly in the tensile mode with shear lips at the sheet surfaces. It is not clear how this could explain the deviations.

\section{Results of a test with an unintentional peak load}

In the first test with spectrum 4 on a 2024-T3 specimen a high peak load was unintentionally applied due to some malfunctioning of the fatigue machine. Some further fatigue 
crack growth did still occur, followed by full crack arrest, see the crack growth curve in Fig.16a. The figure also shows the crack growth curve of the second specimen tested with spectrum 4 . The first parts of the two curves are practically identical. After crack arrest of the $1^{\text {st }}$ specimen, the crack surface was opened by loading the specimen statically until failure. The fracture surface of one crack tip is presented in Fig.16b. It shows that the crack front before the peak load occurred was slightly curved. During the peak load some static crack extension has occurred in region $\mathrm{A}$, as confirmed in the SEM by the typical ductile void formation on the fracture surface. It was followed by some limited crack extension by the continued fatigue loading. In the light area B fatigue striations could be observed, although the picture was erratic. Some straightening of the crack front occurred during this fatigue crack extension. The right hand side of Fig.16b shows the static failure area, produced by opening of the fracture surface.

\section{Discussion}

In the present study a large number of fractographic pictures have been examined in the scanning electron microscope. The observations revealed several features bearing upon (i) the fatigue fracture mechanism and (ii) the application of fracture mechanics to fatigue crack growth. Not all observations are essentially new, but in the literature they are not always discussed in the light of the physical relevance with respect to prediction models for fatigue crack growth under VA loading.

\section{Observations on the growth of fatigue cracks in the two aluminium alloys}

A most prominent characteristic feature is associated with the geometry of the crack front. In fracture mechanics the crack front of a fatigue crack in the tensile mode is generally assumed to be a smooth and continuous line in a mode I plane. It is well-known that this is not true on a micro level $[5,6,7]$. Micrographs of the present study have confirmed again that the crack front in reality exhibits various local curvatures, sometimes with a rather tortuous $3 \mathrm{~d}$ character. An example is shown in Fig.17. In this figure the striations of the BL cycles in the areas A1 to A4 can easily be observed. Between $\mathrm{A} 1$ and $\mathrm{A} 2$ and between $\mathrm{A} 2$ and $\mathrm{A} 3$ the crack front appears to be rather erratic. Going from A3 to A4, two areas with visible striations, the angle of the crack growth direction is abruptly changing. In the B1 block with 10 striations of the 
OL cycles the crack front is still far from uniform.

Ridges in the crack growth direction between areas with striations are a common characteristic for Al-alloys. They are obviously present in Figs 7 and 10. Possible origins of the ridges will not be discussed in detail here. The ridges are usually associated with some characteristic features of the material structure, such as (sub) grain boundaries and inclusions. Crack growth along the crack front in slightly different directions may also be involved. In this case, crack growth at the two sides of a ridge occurs at slightly staggered levels with the ridge as a kind of a transition. It is of some interest that small ridges were sometimes observed in the BL bands between bands of OL cycles, see Figure 18. Quite often these small ridges in the growing direction did not continue in the next band of OL cycles. It indicates some kind of structural sensitive fatigue cracking, which seems to be more significant for the smaller BL cycles than for the larger OL cycles. For micro structurally small cracks, a structural sensitive fatigue crack growth behaviour should be expected as discussed by Miller [8]. But it was also noticed for large cracks, noteworthy by Stubbington and Gunn [9] for a Ti-6-4 alloy. They showed that fatigue precracking of a CTS specimen at a low stress amplitude caused structural sensitive cracking on preferred crystal planes. The crack surface then was relatively rough and an irregular crack front was obtained. It led to a high fracture toughness. However, fatigue precracking at a high stress amplitude produced a flat structure-insensitive crack plane, and the $\mathrm{K}_{\mathrm{Ic}}$ was $33 \%$ lower. Although structural sensitive crack growth for Al-alloys could be less important than for Ti-alloys, and some other alloys as well, it can not be fully ruled out. The topic, however, is not considered in prediction models.

\section{Observations on crack growth interaction effects between small BL cycles and larger $O L$ cycles}

Crack growth retardation occurred in all VA experiments on specimens of the two Alalloys (Figs.4 and 5). The retardation for spectra 2, 4 and 5 was not large, probably due to the fairly small OL ratio. It could be of interest to do similar spectrum tests with a more significant difference between the OL cycles and BL cycles.

The occurrence of delayed retardation is not indicated by the visual crack growth records. However, it was shown by the SEM pictures in two ways. Firstly, measurements of the band width corresponding to the blocks of BL cycles in spectrum 4 (Fig.10b) revealed a faster crack growth in the first cycles after the OL cycles (Fig.11) followed by a slower crack growth later. 
Secondly, observations on the striations of the BL cycles also indicated the occurrence of the delayed retardation, see Figs. 13 and 14.

Delayed retardation was shown in various literature sources, while it was also confirmed by fractographic examinations, including the acceleration directly after the OLs (e.g. in [10-12]). This observation is important for the evaluation of crack growth prediction models. Older crack closure models predict an immediate maximum retardation, because it is assumed that the crack closure level goes down to its maximum immediately after the OL. This is apparently in conflict with the fractographic evidence. The strip yield models [13-15] do not a priori assume a quantitative crack closure behaviour. The plastic wake field of a growing fatigue crack, responsible for the occurrence of crack closure, is predicted by these models. Some prediction results on delayed crack growth retardation has been published $[16,17]$, but the validation is still not abundant.

As discussed before, an unintentional peak load occurred in a test with spectrum 4 on a 2024-T3 specimen. As shown by Fig.16, it did not immediately stop fatigue crack growth. The crack was arrested after some $0.5 \mathrm{~mm}$ crack extension. The peak load stress was $140 \mathrm{MPa}$, which under plane stress will give a plastic zone size in the order of $2.5 \mathrm{~mm}$. It would be of interest to see whether a strip yield model can predict such a crack arrest behaviour.

While OLs give crack growth retardation during the BL cycles, the BL cycles might cause crack growth acceleration during the OL cycles. Although the fractographic evidence of the present study is limited, indications on such an acceleration were not obtained. De Koning et al. [18] introduced the concept of primary and secondary plasticity at the crack tip, and its significance for fatigue crack growth. Primary crack tip plasticity is plastic deformation occurring in material that has not yet been plastically deformed by previous cycles, i.e. elastic material so far. Secondary crack tip plasticity occurs in material that was already plastically deformed in previous cycles. During primary crack tip plasticity the incremental crack extension for the same $\mathrm{K}$-increment is larger than during secondary crack tip plasticity. As discussed by the present author [19], this can lead to a giant striation in the first cycle of a block of OL cycles. Although this was confirmed by fractographic evidence in [12], it was not observed in the present experiments. This could be due to the relatively low OL ratios. More systematic fractography on this issue should be recommended in view of the development of prediction models for VA loading. 


\section{Reconstruction of crack growth and marker loads}

Marker loads were applied in research programs for the purpose of a fractographic reconstruction of fatigue crack growth curves [e.g.20-23], and more in particular for the development of the shape of fatigue cracks with curved crack fronts, such as surface cracks, corner cracks, or oblique crack fronts under combined tension and bending. It is generally required that the marker load cycles should have a negligible effect on crack growth of the BL cycles. In the present test with spectrum 5 (Fig.9) a satisfactory reconstruction of the crack growth curve was possible, although it required a careful examination of the fracture surface. However, the marker loads were OLs, which have a retardation effect on crack growth. In our test the retardation effect was limited (Fig.5), due to small numbers of OL cycles and a modest $\mathrm{OL}$ ratio. For certain research purposes it could be advantageous to use such marker load cycles, if the marker striations are more easily detectable in the SEM. Especially, for the crack shape development of invisible cracks, it might be useful.

\section{Fatigue crack growth and the similarity approach}

Predictions on fatigue crack growth under VA loading are generally based on a similarity concept. Crack growth rates for VA loading are then obtained from crack growth data for CA loading, which are supposed to be basic material fatigue data. The similarity implies that a predicted $\Delta \mathrm{K}_{\text {eff }}$ for a load cycle of a VA load history should give the same crack extension as obtained under CA loading for the same $\Delta \mathrm{K}_{\text {eff }}$ (*) $^{*}$ This can be correct only if the mechanism of fatigue crack growth is similar. As noted before, structural sensitive crack growth can depend on the cyclic stress level (better to say, the cyclic crack tip stress intensity). It can lead to different crack front geometries, i.e. under VA loading, a crack front geometry may occur, that would not be present under CA loading at the same $\Delta \mathrm{K}_{\text {eff. }}$ Another source of dissimilar crack fronts, recognized earlier [24], is associated with the development of shear lips, which also depends on the cyclic stress level. The shear lip width under VA loading depends on all load cycles of the load spectrum, but the width is not necessarily equal to the shear lip width at the applicable $\Delta \mathrm{K}_{\mathrm{eff}}$ in a CA test. This incompatibility can lead to interaction effects not accounted for in the present similarity based prediction models. Whether such dissimilarities are significant form an

(*) Actually, the primary/secondary plastic flow concept of De Koning [18] is an essential addition to the approach, but it is still using $\mathrm{K}$-values to define similar conditions under VA and CA loading. 
engineering point of view should be assessed by empirical evidence. However, it should be recognized that fractographic observations are essential to reveal such dissimilarities of the fatigue fracture mechanisms under VA and CA loading.

\section{Conclusions}

Fatigue crack growth tests were carried out on 2024-T3 (bare) and 7075-T6 (clad) central cracked specimens. Variable-amplitude (VA) load spectra were adopted with periodic overload cycles (OLs) added to constant-amplitude base line (BL) cycles. The purpose of the experiments was to study the fracture surfaces in the scanning electron microscope in order to discover possible interaction effects in more detail than it can be done by using the crack growth records only. The load spectra are shown in Fig.1. The analysis of a large number of fractographic pictures has revealed information with respect to fatigue crack growth in the two Al-alloys, bearing upon aspects of the fatigue crack growth mechanism and on the relevance of this information for prediction models based on fracture mechanics. This is summarized in the conclusions below, which apply to macro cracks.

1. In most cases, the striation patterns of the fractographic pictures could be easily related to the load history of the 5 spectra, because the OL striations were easily observed. Striations of the BL cycles could sometimes be observed. The fractographic pictures indicated the occurrence of scatter of the crack growth rate along the crack front, as well as in the growing direction. Sometimes quite erratic pictures with a tortuous appearance were obtained, although they could still be related to the load history if a careful examination was carried out. Knowledge of the striation pattern to be expected is then important.

2. A satisfactory agreement was found between crack growth rates derived from SEM pictures and from visual records.

3. A comparison of the spectrum test results to CA results indicated crack growth retardation in all VA tests. The retardation was modest for spectra 1, 2 and 4 (Fig.4) and more significant for spectrum 3 (Fig.5). The larger retardation was associated with a higher OL ratio in spectrum 3 . The same OL ratio used in spectrum 5 gave again a limited retardation because of the small number OL cycles.

4. Delayed retardation after OLs was observed fractographically in two ways: (i) by 
measuring the band width in the SEM of blocks of BL cycles, and (ii) by measuring striation spacings of BL cycles following the OLs.

5. Fractography indicated similar crack growth of the BL cycles after a block of $10 \mathrm{OL}$ cycles and after a single OL cycle.

6. Striations of BL cycles could sometimes be observed, but in other cases quasi-striations were obtained at low crack rates. The latter ones can not be used to measure local da/dN values.

7. Fractography did not indicate crack growth acceleration during the blocks of $10 \mathrm{OL}$ cycles.

8. A fully satisfactory reconstruction of a crack growth curve was obtained by SEM measurements of the crack length corresponding to the OL cycles. It requires that no striations of the OLs are missed in the SEM examination.

9. Crack arrest occurred in one test with an occasionally high peak load, but after some crack growth (about $0.5 \mathrm{~mm}$ ) had occurred into the plastic zone of the peak load.

10. Indications of a structural sensitive crack growth mechanism were obtained. The sensitivity was depending on the cyclic stress level. Such a sensitivity is not accounted for in crack growth prediction models.

11. Fractography is indispensable to the evaluation of fatigue crack growth prediction models. Limitations of the similarity approach for VA predictions should be explored by fractographic research.

Acknowledgment: Experimental assistance of Jan Snijder, Berthil Grashof and Frans Oostrum is greatly acknowledged.

\section{References}

[1] J. Schijve (1998) Data collection of a fractographic investigation on fatigue crack growth in aluminium alloys under simple variable-amplitude loading. Fac. Aerospace Engng., Delft, Doc. b2-98-04.

[2] J. Schijve (1981) Some formulas for the crack opening stress level. Engng. Fract. Mech. 14, 461-465.

[3] I. Nedbal, J. Siegl and J. Kunz (1989) Relation between striation spacing and fatigue crack growth rate in Al-alloy sheets. Advances of Fracture Research (Proc. ICF 7, Houston). Pergamon Press, 3843-3491.

[4] R.J.H. Wanhill (1988) Low stress intensity fatigue crack growth in 2024-T3 and T351. Engng. Fract. Mech. 30, 233-260. 
[4a] R.W. Hertzberg and W.J. Mills (1976) Character of fatigue fracture surface micro morphology in the ultra-low growth rate regime. ASTM STP 600, 220-234.

[5] C.Q. Bowles (1978) The role of environment, frequency and wave shape during fatigue crack growth in aluminum alloys. Doctor Thesis, Delft Un. of Tech.

[6] C.Q. Bowles and J. Schijve (1983) Crack tip geometry for fatigue cracks grown in air and vacuum. ASTM STP $811,400-426$

[7] J. Schijve (1982) Difference between the growth of small and large fatigue cracks. The relation to threshold K-values. Fatigue Thresholds, Fundamentals and Engineering Applications. Proc. Int. Conf. Stockholm 1981. EMAS Warley, 881-908.

[8] K.J.Miller (1993) The two thresholds of fatigue behaviour. Fatigue Fract. Eng. Mater. Struct. 16, 931-939.

[9] C.A. Stubbington and N.J.F. Gunn (1977) Effects of fatigue crack front geometry and crystallography on the fracture toughness of an Ti-6Al-4V alloy. Roy. Aero. Est., TR 77158, Farnborough.

[10] H.Homma, H. Koksaka and H. Nakazawa (1984) Numerical analysis of fatigue striations after a single overload. Fatigue 84, Proc.Int.Conf. on Fatigue Thresholds. EMAS, 927-936.

[11] S. Zhang, R.Marissen, K.Schulte, K.K.Trautmann, H.Nowack and J.Schijve (1987) Crack propagation studies on Al 7475 on the basis of constant amplitude and selective variable amplitude loading histories. Fatigue Fract. Engng Mater. Struct. 4, 315-332.

[12] M.R. Ling and J. Schijve (1990) Fractographic analysis of crack growth and shear lip development under simple variable-amplitude loading. Fatigue Fract. Engng Mater. Struct. 13, 443-456.

[13] J.C.Newman,Jr. (1981) A Crack-Closure Model for Predicting Fatigue Crack Growth under Aircraft Spectrum Loading. ASTM STP 748, 53-84.

[14] D.J.Dougherty, A.U. de Koning and B.M.Hillberry (1992) Modelling High Crack Growth Rates under Variable Amplitude Loading. ASTM STP 1122, 214-233.

[15] G.S.Wang and A.F.Blom (1991) A Strip Model for Fatigue Crack Growth Predictions under General Load Conditions. Eng. Fract. Mech., 40, 507-533.

[16] A.U. de Koning and G. Liefting (1988) Analysis of crack opening behavior by application of a discretized strip yield model. ASTM STP 982, 437-458.

[17] M. Skorupa, J. Schijve, A. Skorupa and A. Zachwieja (1998) Experimental results and predictions of crack growth in a structural steel under periodically applied single and multiple overloads. Paper OMAE '98, Conf., Lisbon (to be published).

[18] A.U. de Koning and D.J. Dougherty (1989) Prediction of low and high crack growth rates under constant and variable amplitude loading. Fatigue crack growth under variable amplitude loading, 208-217. Elsevier, Amsterdam.

[19] J. Schijve (1992) Fundamental aspects of predictions on fatigue crack growth under variableamplitude loading. Theoretical Concepts and Numerical Analysis of Fatigue. EMAS, 111-130.

[20] R. Sunder and P.K. Dash (1982) Measurement of Fatigue Crack Closure Through Electron Microscopy. Int.J. Fatigue, 4, 97-105.

[21] Ichsan S. Putra and J. Schijve (1992) Crack Opening Stress Measurements of Surface Cracks in 7075-T6 Al Alloy Plate Specimens Through Electron Fractography. Fatigue Fract. Engng. Mater. Struct., 15, 323-338.

[22 ] R.S. Piascik. and S.A. Willard (1997) The characteristics of fatigue damage in the fuselage riveted lap splice joint. NASA / TP-97-206257.

[23] S.A. Fawaz (1997) Fatigue crack growth in riveted joints. Doctor thesis, Delft Un. of Technology.

[24] J. Schijve (1974) Fatigue damage accumulation and incompatible crack front orientation. Eng.Fracture Mechanics, 6, 245-252. 

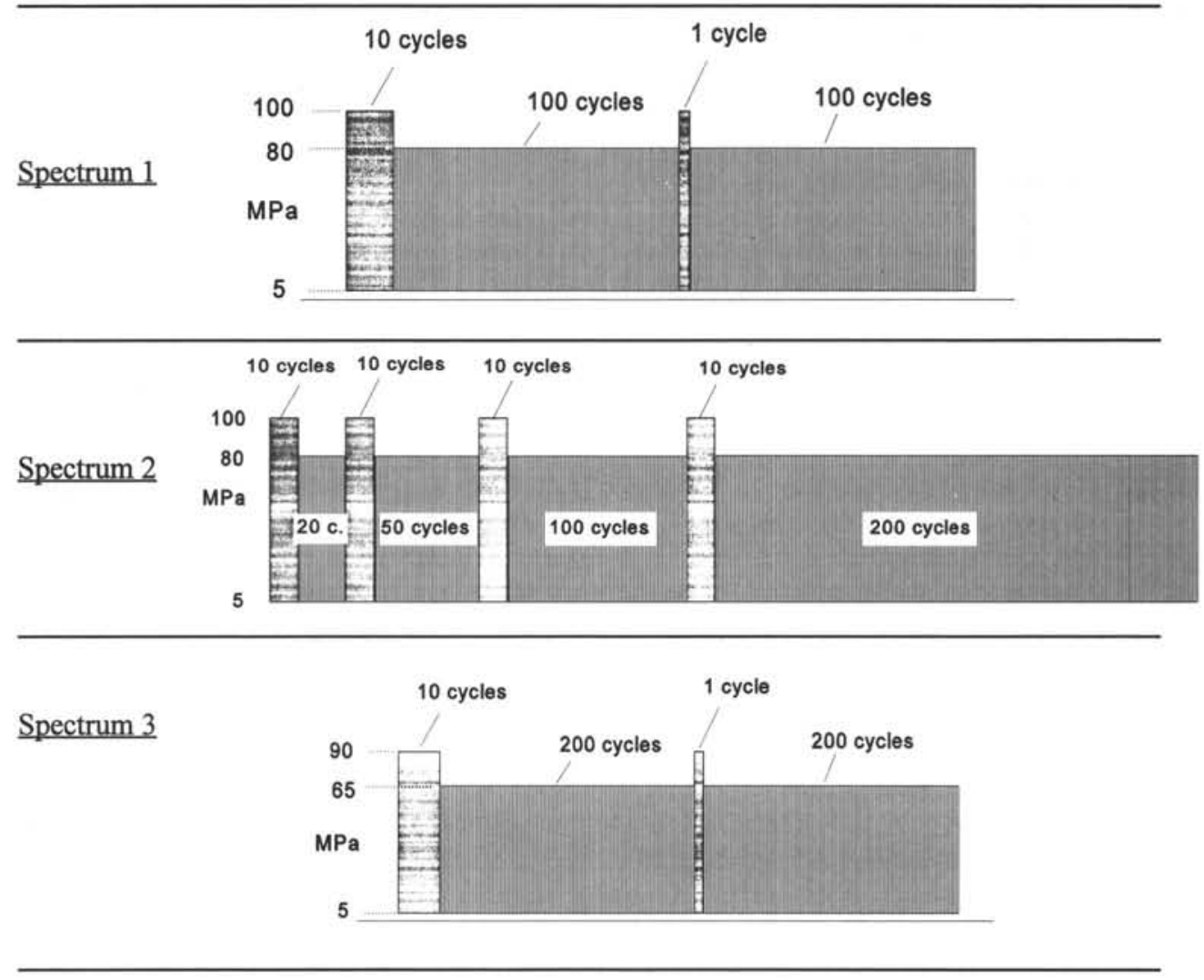

\section{Spectrum 4}

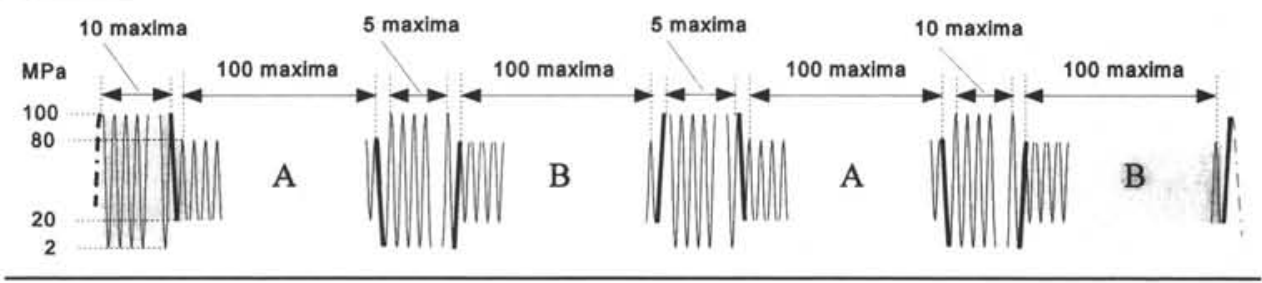

Spectrum 5

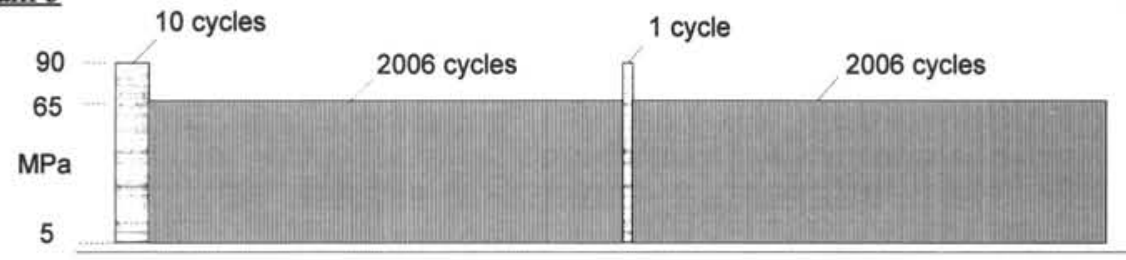

Figure 1: Survey of the five load histories. 


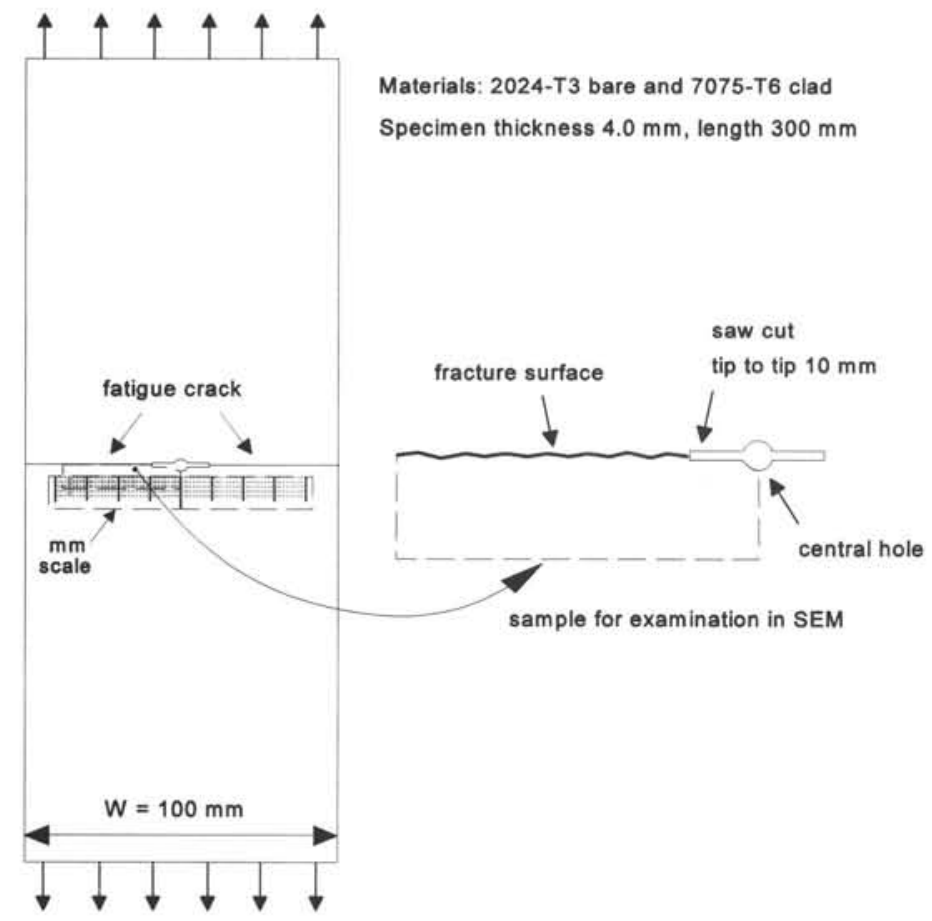

Fig. 2: Specimen

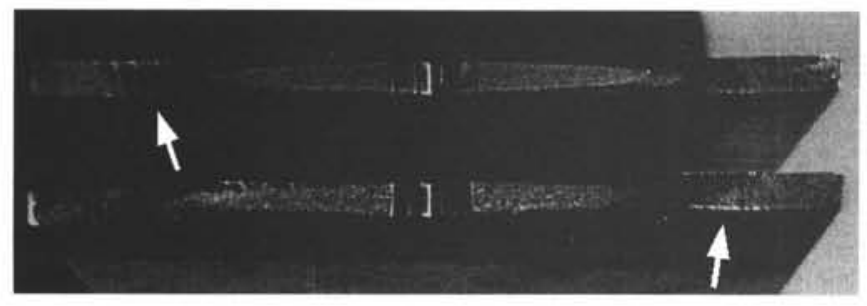

Fig. 6: Fracture surfaces of specimens of 2024 (top) and 7075 (bottom), tested with load spectrum 1 . 


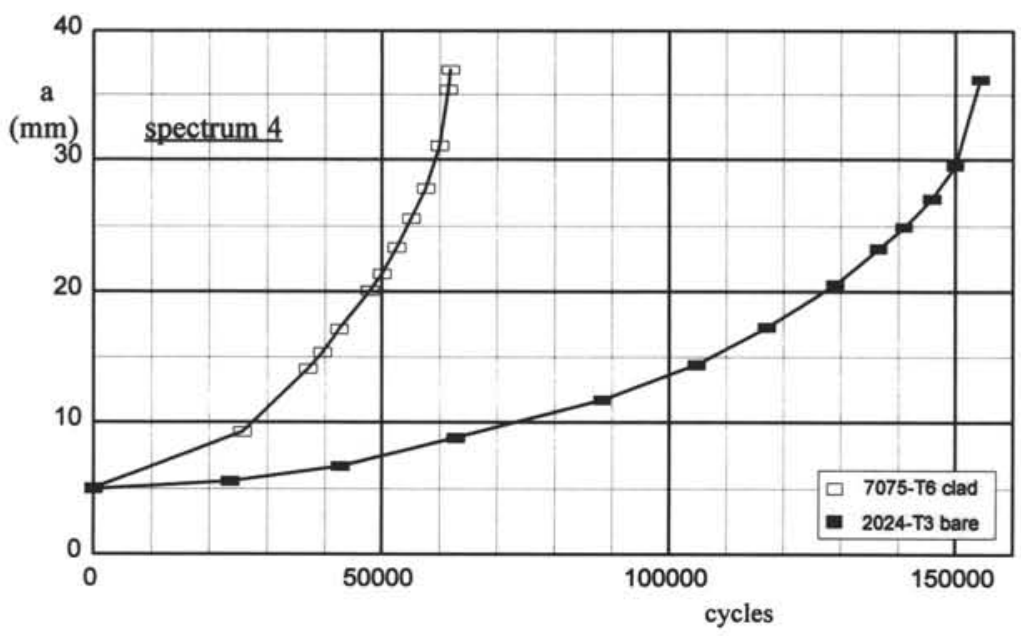

Fig.3a: Crack growth curves, visual observations.
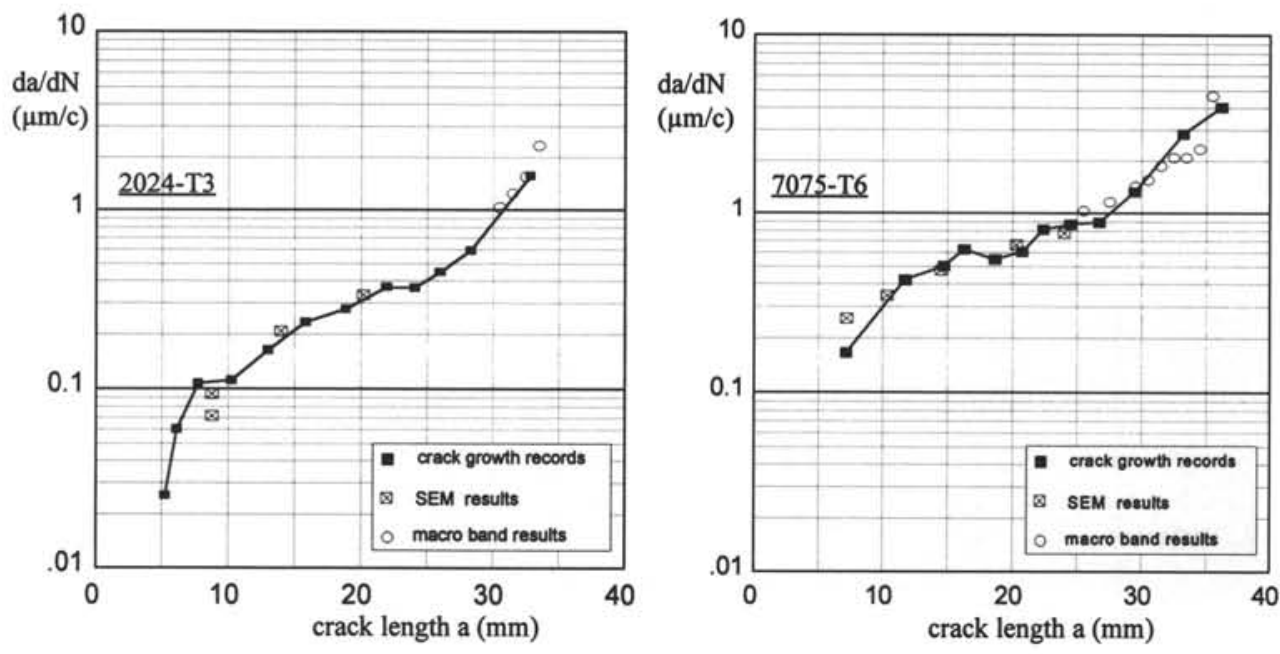

Figure 3b: Crack growth rates, fractographic results compared to results from visual observations.

Fig.3: Crack growth results for spectrum 4 

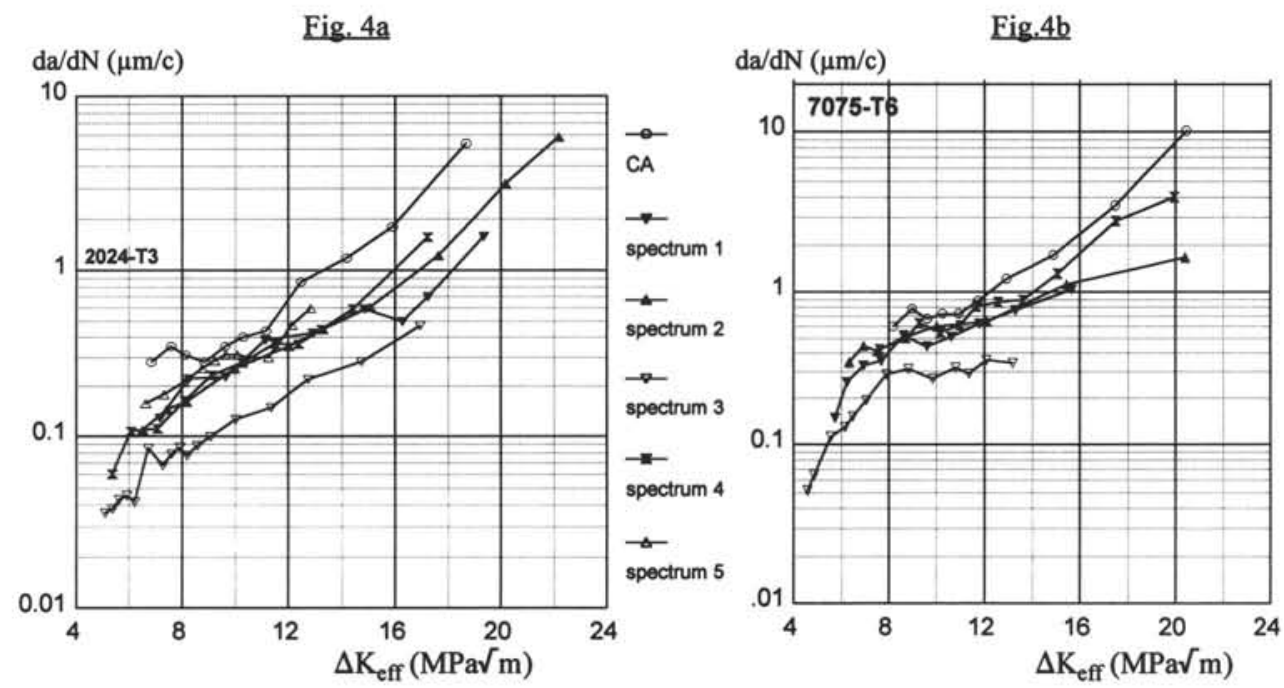

Fig.4: Crack growth rates as a function of $\Delta \mathrm{K}_{\text {eff }}$ for the base line cycles.
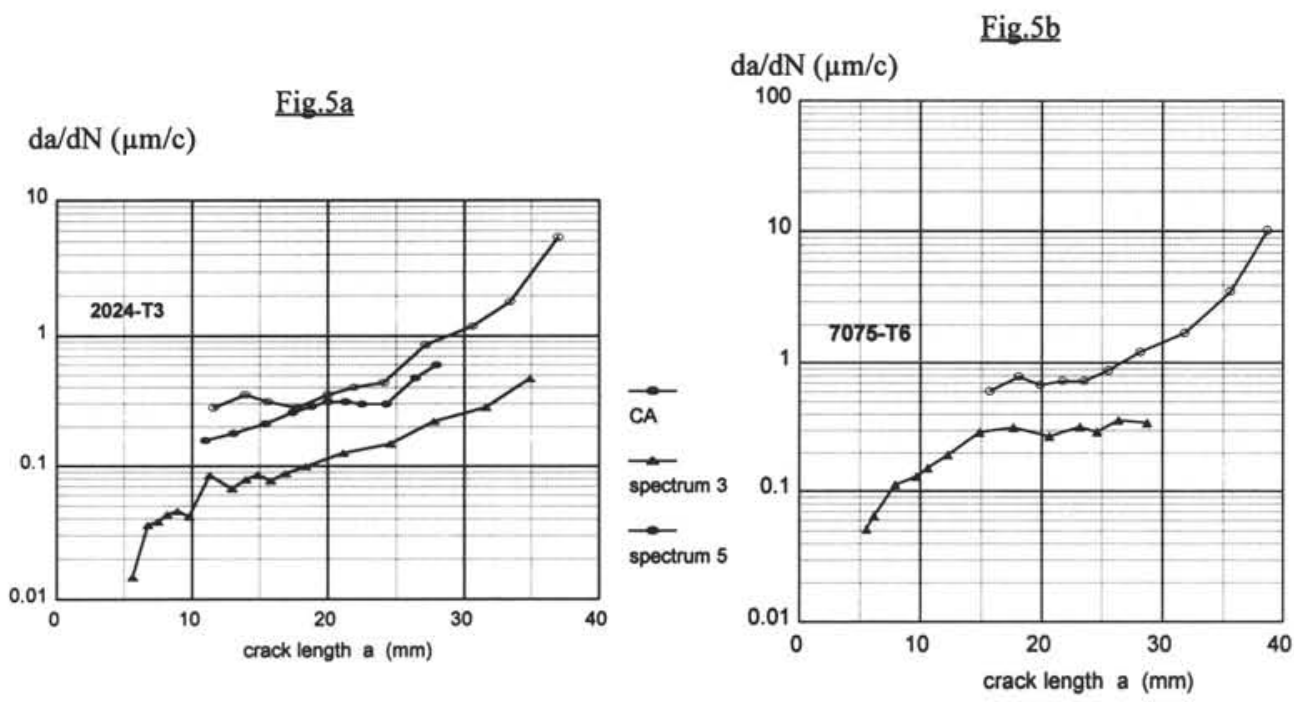

Fig.5: Crack growth rates as a function of the crack length. 


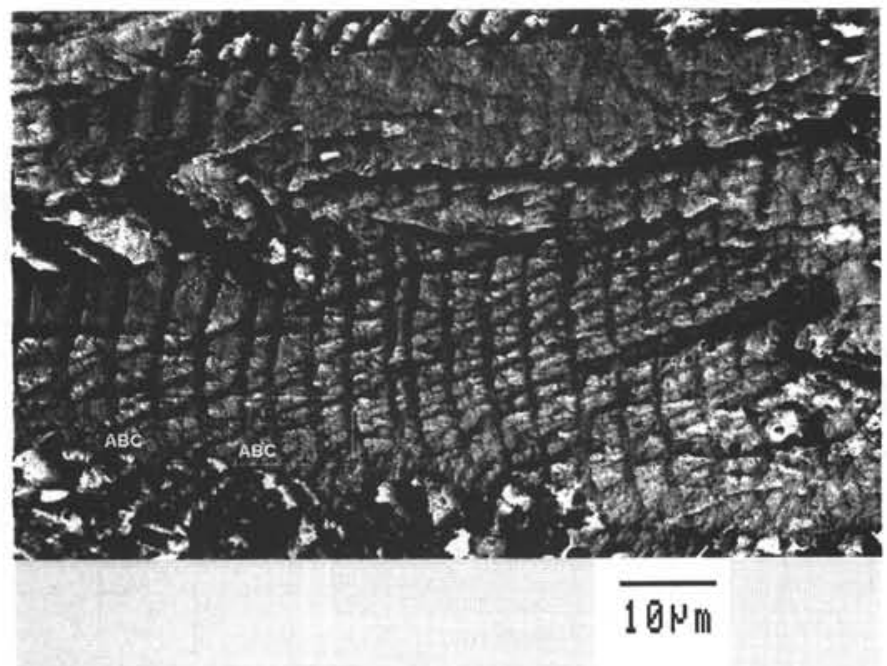

Fig.7a: Material 2024-T3, spectrum 1, $a=5.1 \mathrm{~mm}$. Crack growth from right to left. Some 20 heavy bands correspond to blocks of 10 OL cycles. Between two heavy bands one faint line of a single OL cycle.

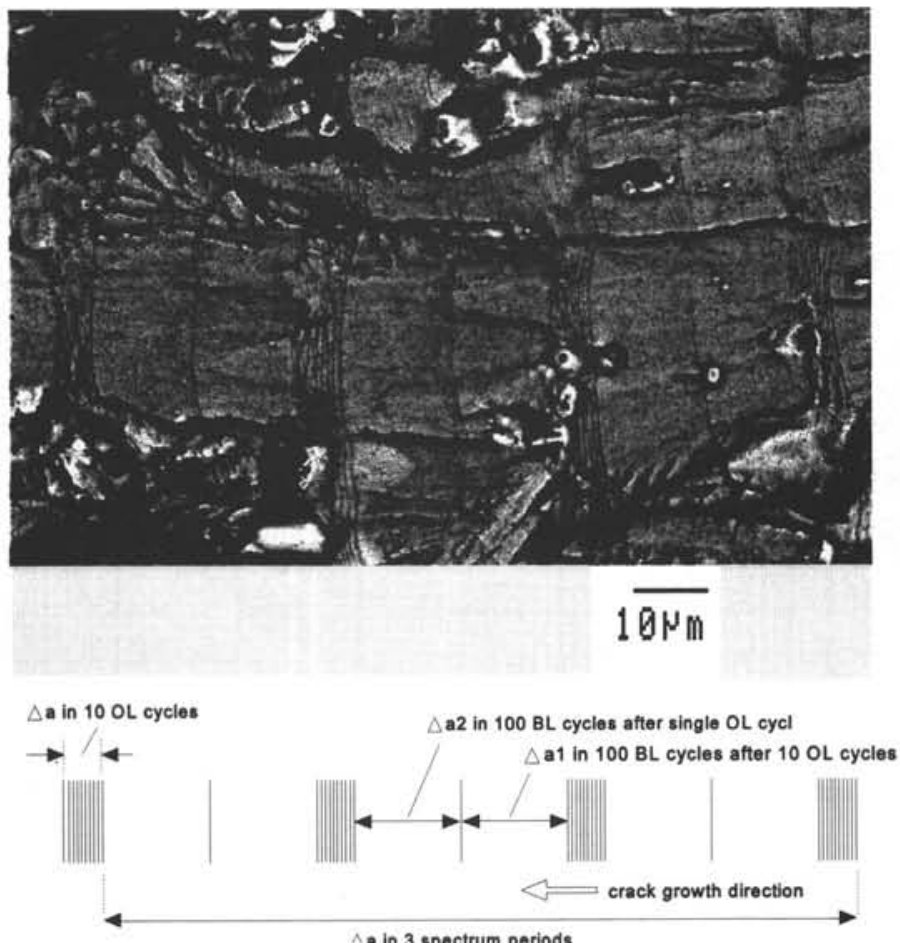

Fig. 7b: Material 2024-T3, spectrum 1, $a=9.1 \mathrm{~mm}$. The four bands with 10 striations correspond to blocks of $10 \mathrm{OL}$ cycles. Between two such bands is one line of a single OL cycle. 


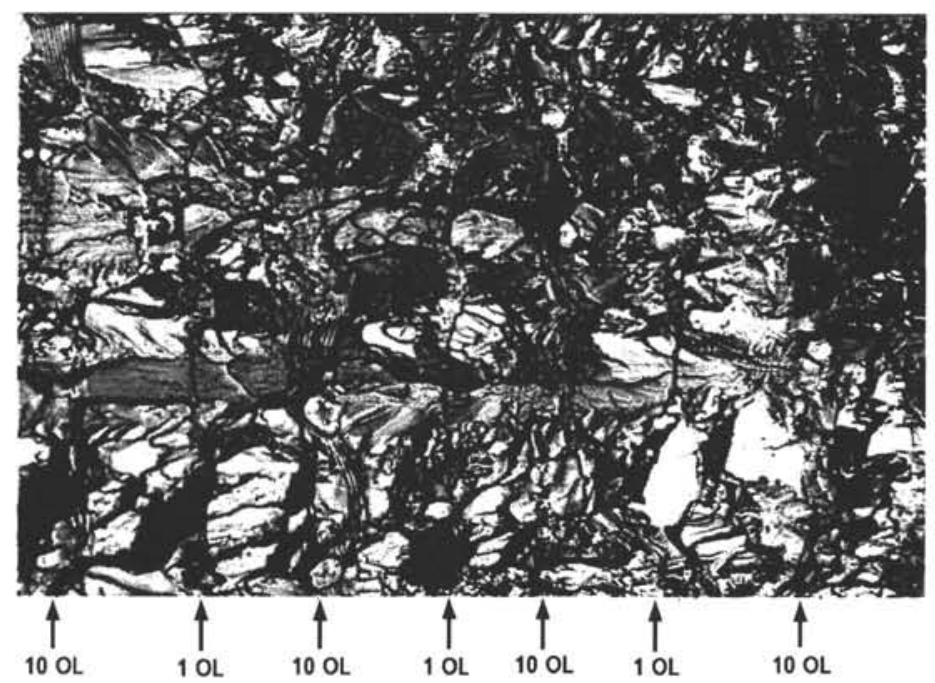

Fig. 8: Fractographic picture of 7075-T6 specimen tested under spectrum 3.

Example of erratic pattern of OL cycle striations. Arrows indicate approximate locations of OL bands.

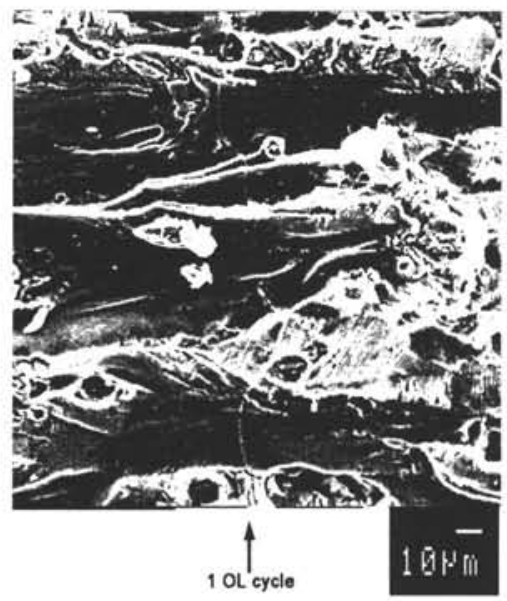

Fig.9a: SEM picture at crack length $\mathrm{a}=16.35 \mathrm{~mm}$. A striation of a single $\mathrm{OL}$ cycle is visible.

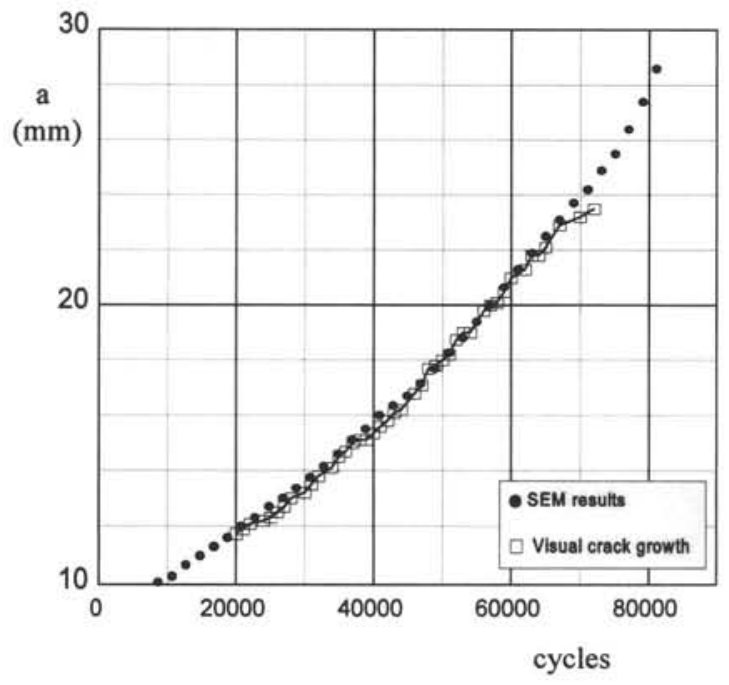

Fig.9b: Crack growth curve reconstructed from SEM measurements. Comparison to visually recorded crack growth.

Fig. 9: Reconstruction of crack growth curve by using X-values of SEM observations on the striations of the OL cycles.Specimen 2024-5 tested under spectrum 5. 


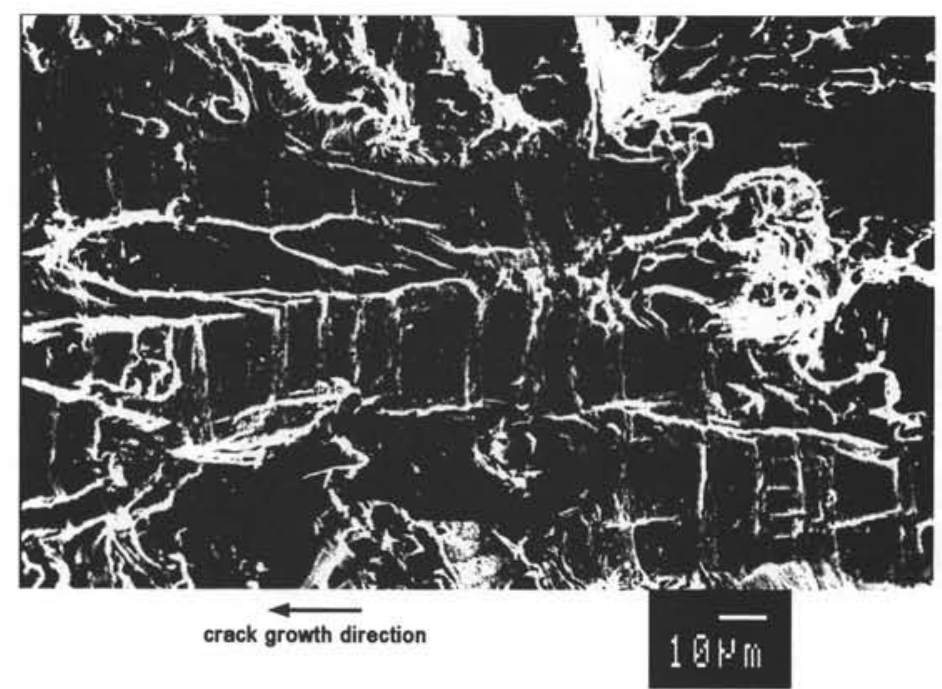

Fig. 10a: Material 2024-T3, $a=10.4 \mathrm{~mm}$. Groups of the four bands of OL cycles of spectrum 2.

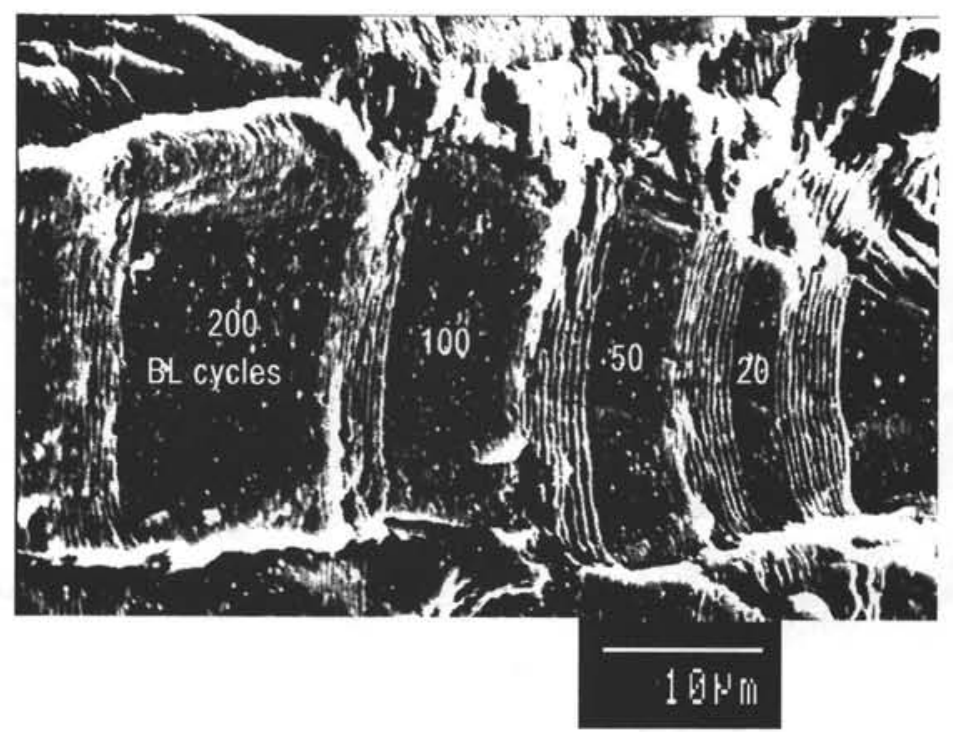

Fig. 10b: Detail of Fig.9a. OL blocks with 10 striations each and intermediate areas of BS cycles. 


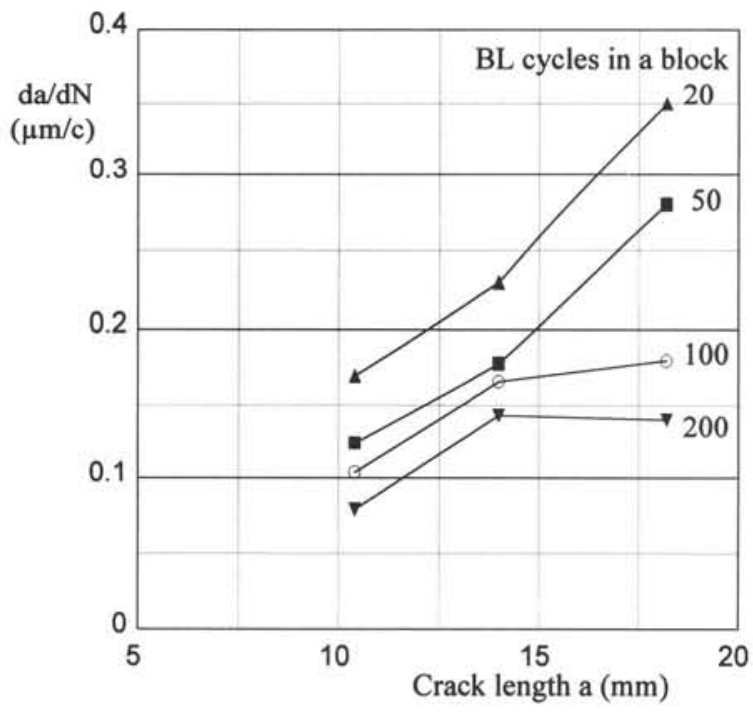

Fig.11: Crack growth rates in the four BL blocks of spectrum 2. Material 2024-T3. Results of measurements in the SEM.

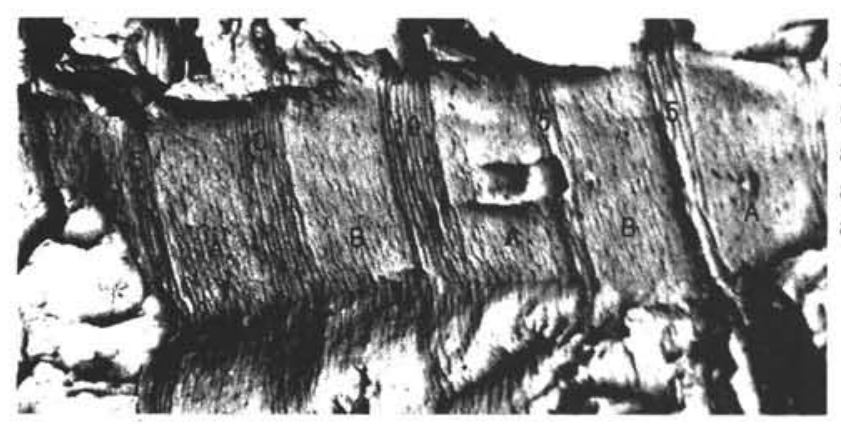

2024-T3

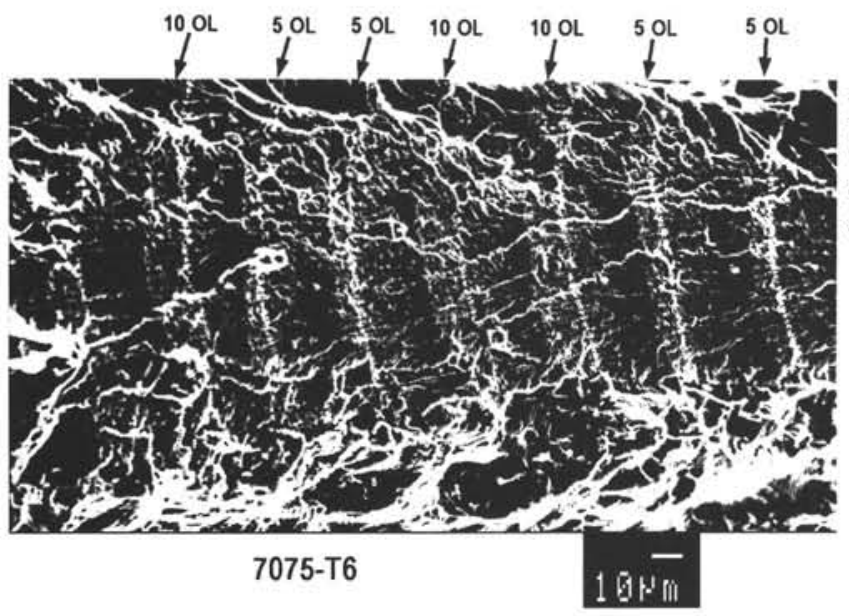

Fig.12a:

Specimen 2024-4, spectrum 4, $\mathrm{a}=8.75 \mathrm{~mm}$. OL blocks with 5 and $10 \mathrm{OL}$ cycles. BL blocks A and B, see Fig.1.
Fig.12b:

Specimen 7075-4, spectrum 4, $a=10.25 \mathrm{~mm}$. OL blocks with 5 and $10 \mathrm{OL}$ cycles. 


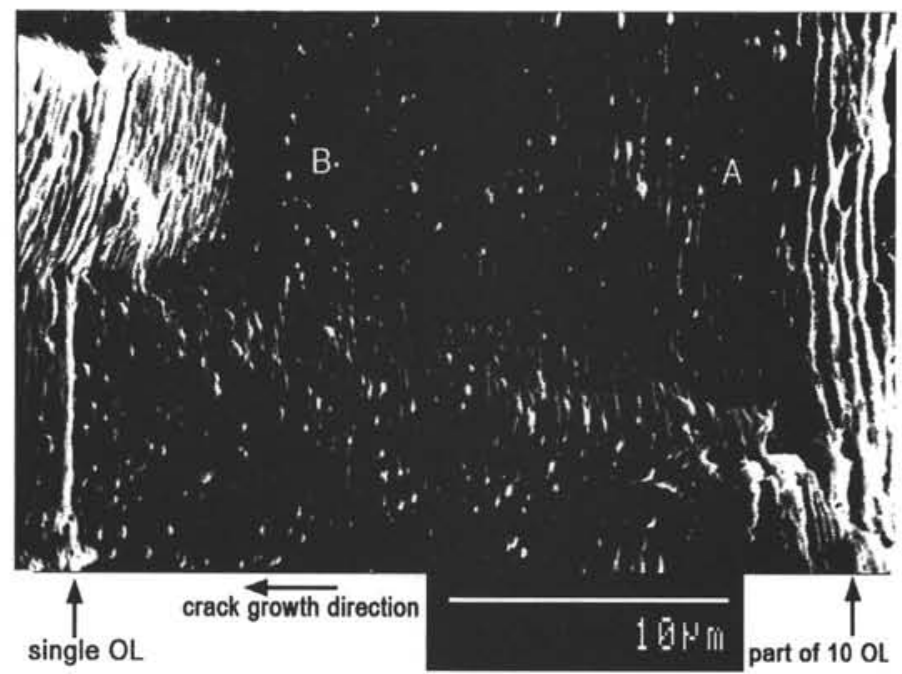

Fig. 13a: Spectrum 1, 2024-T3 specimen, $a=17.6 \mathrm{~mm}$.

$100 \mathrm{BL}$ striations between $\mathrm{OL}$ cycles suggest some delayed retardation.

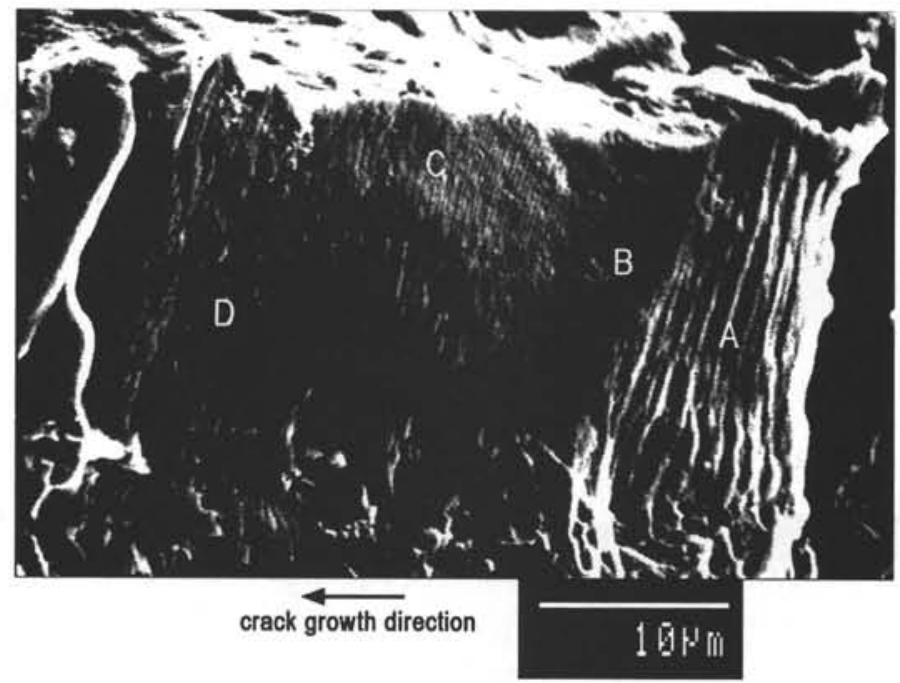

Fig. 13b: $\quad$ Spectrum 2, 7075-T6 specimen, $a=17.6 \mathrm{~mm}$.

Striations in block of $100 \mathrm{BL}$ cycles between OL cycles.

$\mathrm{A}=$ area of $10 \mathrm{OL}$ cycles striations

$\mathrm{B}=$ area of wider $\mathrm{BL}$ striation spacings. $\mathrm{C}=$ area of finer $\mathrm{BL}$ striation spacings.

$\mathrm{D}=$ area of quasi striation.

Fig.13: Delayed retardation indicated by striations of the BL cycles. 


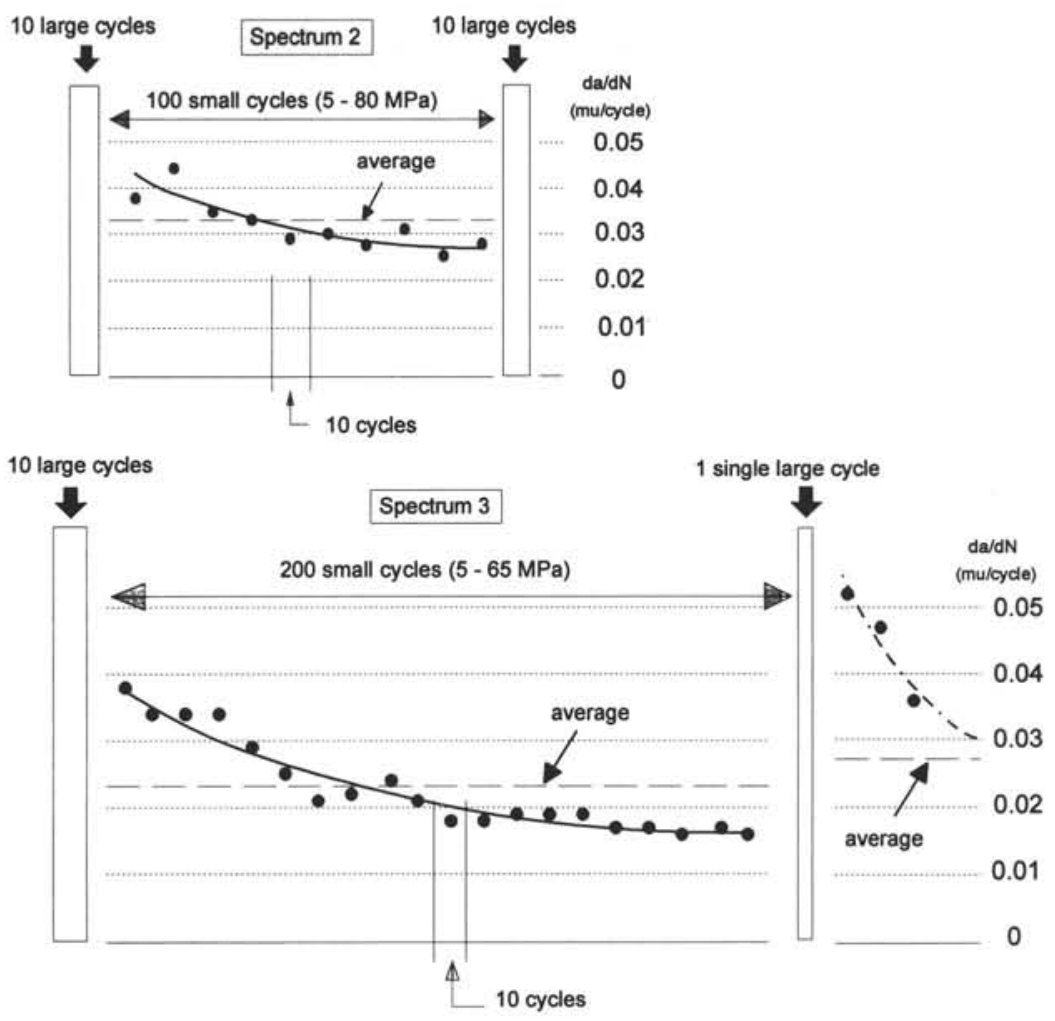

Fig.14: Delayed retardation as derived from fractographic SEM pictures of 7075-T6 specimens. 


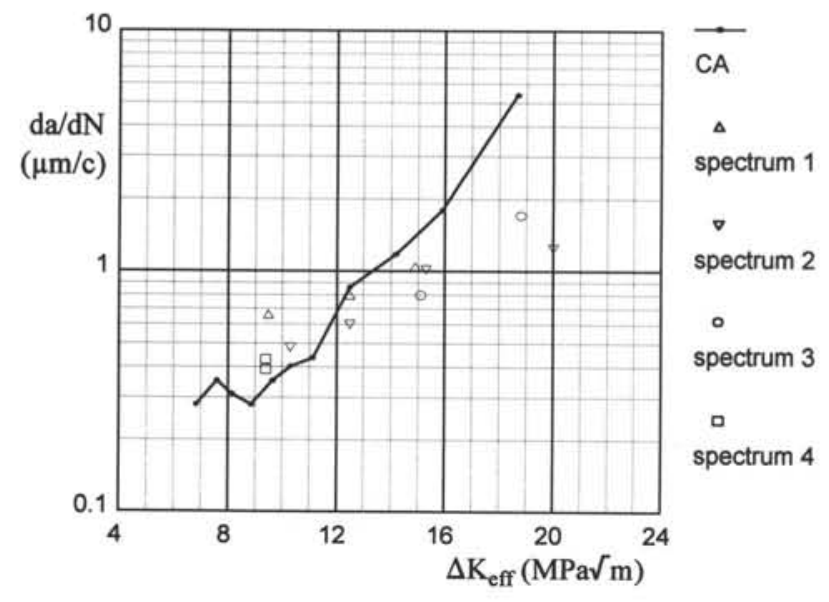

Fig.15: Crack growthe rates of the OL cycles in batches of $10 \mathrm{OL}$ cycles. Results of fractographic pictures.

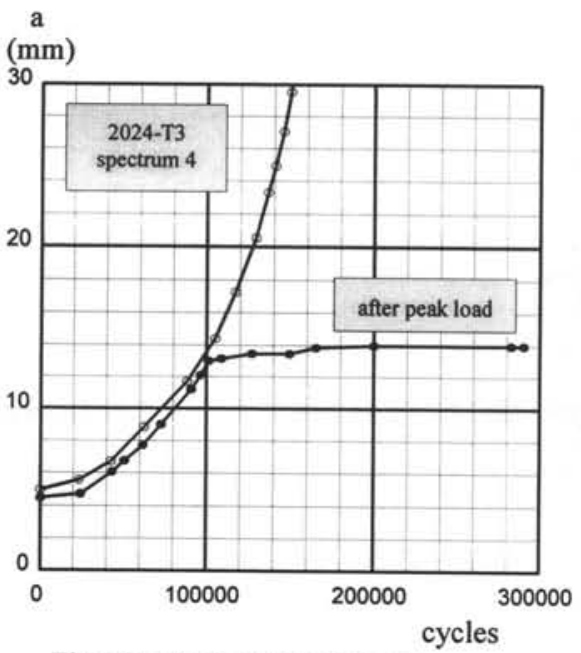

Fig.16a: Crack growth curves

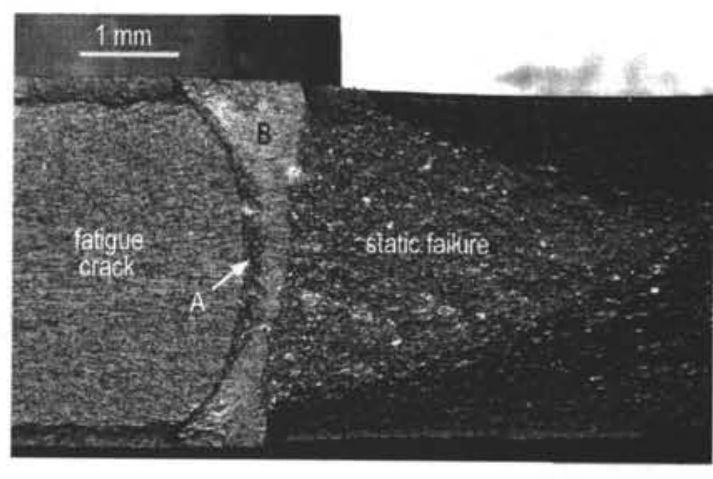

Fig.16b: Crack tip area of specimen with unintentional peak load.

Fig.16: Two 2024-T3 specimens loaded with spectrum 4, first specimen with an unintentional peak load at $a=13 \mathrm{~mm}$. 


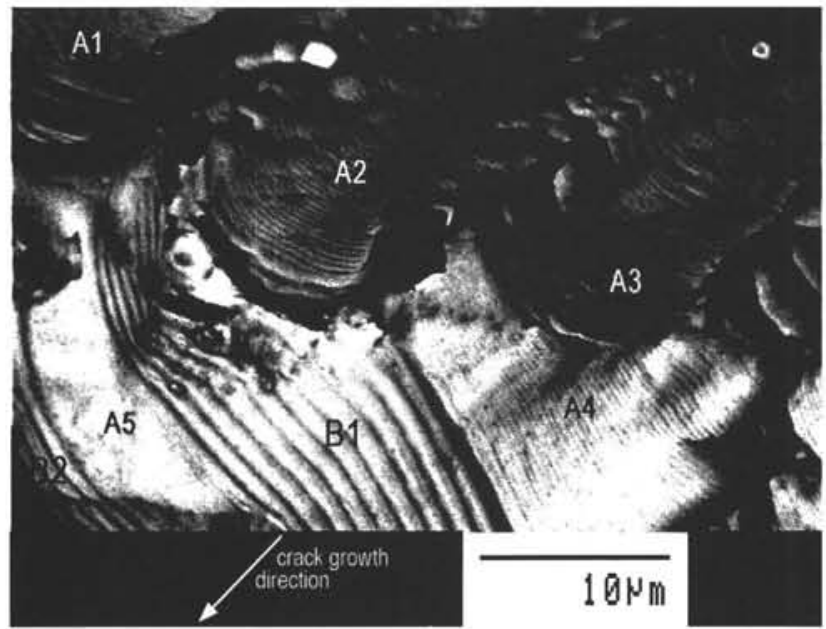

Spectrum 2, 7075-T6 specimen, a $=9.3 \mathrm{~mm}$.

A1-A4: striations of BL cycles of 200-cycle block.

A5: striations of BL cycles of 20-cycle block.

$\mathrm{B} 1$ and B2: striations of blocks of $10 \mathrm{OL}$ cycles.

Fig.17: 3-d character of fatigue crack.

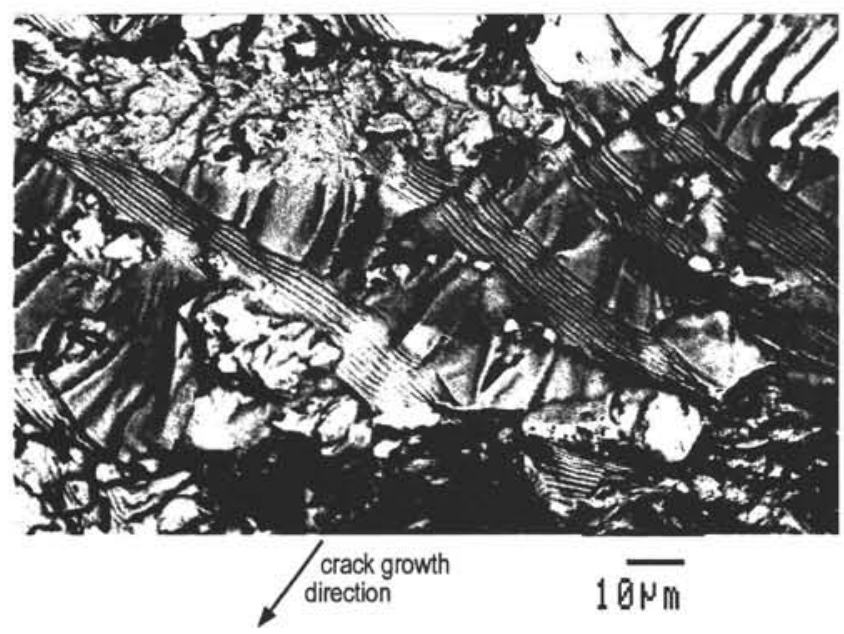

Spectrum 2, 7075-T6 specimen, $a=12.7 \mathrm{~mm}$

Fig.18: Difference between fracture surfaces of the blocks of BL cycles and OL cycles. 



\section{Series 01: Aerodynamics}

01. F. Motallebi, 'Prediction of Mean Flow Data for Adiabatic 2-D Compressible Turbulent Boundary Layers'

1997 / VI + 90 pages / ISBN 90-407-1564-5

02. P.E. Skåre, 'Flow Measurements for an Afterbody in a Vertical Wind Tunnel'

1997 / XIV + 98 pages / ISBN 90-407-1565-3

03. B.W. van Oudheusden, 'Investigation of Large-Amplitude 1-DOF Rotational Galloping'

1998 / IV + 100 pages / ISBN 90-407-1566-1

04. E.M. Houtman / W.J. Bannink / B.H. Timmerman, 'Experimental and Computational Study of a Blunt Cylinder-Flare Model in High Supersonic Flow'

1998 / VIII + 40 pages / ISBN 90-407-1567-X

05. G.J.D. Zondervan, 'A Review of Propeller Modelling Techniques Based on Euler Methods' 1998 / IV + 84 pages / ISBN 90-407-1568-8

06. M.J. Tummers / D.M. Passchier, 'Spectral Analysis of Individual Realization LDA Data'

1998 / VIII + 36 pages / ISBN 90-407-1569-6

07. P.J.J. Moeleker, 'Linear Temporal Stability Analysis'

1998 / VI + 74 pages / ISBN 90-407-1570-X

08. B.W. van Oudheusden, 'Galloping Behaviour of an Aeroelastic Oscillator with Two Degrees of Freedom'

1998 / IV + 128 pages / ISBN 90-407-1571-8

09. R. Mayer, 'Orientation on Quantitative IR-thermografy in Wall-shear Stress Measurements' 1998 / XII + 108 pages / ISBN 90-407-1572-6

10. K.J.A. Westin / R.A.W.M. Henkes, 'Prediction of Bypass Transition with Differential Reynolds Stress Models'

1998 / VI + 78 pages / ISBN 90-407-1573-4

11. J.L.M. Nijholt, 'Design of a Michelson Interferometer for Quantitative Refraction Index Profile Measurements' 1998 / 60 pages / ISBN 90-407-1574-2

12. R.A.W.M. Henkes / J.L. van Ingen, 'Overview of Stability and Transition in External Aerodynamics' 1998 / IV + 48 pages / ISBN 90-407-1575-0

13. R.A.W.M. Henkes, 'Overview of Turbulence Models for External Aerodynamics'

1998 / IV + 40 pages / ISBN 90-407-1576-9 


\section{Series 02: Flight Mechanics}

01. E. Obert, 'A Method for the Determination of the Effect of Propeller Slipstream on a Static Longitudinal Stability and Control of Multi-engined Aircraft'

1997 / IV + 276 pages / ISBN 90-407-1577-7

02. C. Bill / F. van Dalen / A. Rothwell, 'Aircraft Design and Analysis System (ADAS)'

1997 / X + 222 pages / ISBN 90-407-1578-5

03. E. Torenbeek, 'Optimum Cruise Performance of Subsonic Transport Aircraft'

1998 / X + 66 pages / ISBN 90-407-1579-3

\section{Series 03: Control and Simulation}

01. J.C. Gibson, 'The Definition, Understanding and Design of Aircraft Handling Qualities'

1997 / X + 162 pages / ISBN 90-407-1580-7

02. E.A. Lomonova, 'A System Look at Electromechanical Actuation for Primary Flight Control' 1997 / XIV + 110 pages / ISBN 90-407-1581-5

03. C.A.A.M. van der Linden, 'DASMAT-Delft University Aircraft Simulation Model and Analysis Tool. A Matlab/Simulink Environment for Flight Dynamics and Control Analysis' 1998 / XII + 220 pages / ISBN 90-407-1582-3

04. S.K. Advani, 'The Kinematic Design of Flight SimulatorMotion-Bases' 1998 / XVIII + 244 pages / ISBN 90-407-1671-4

05. J.M. Maciejowski, 'Predictive Control. A Lecture Course Given in the Aerospace Engineering Faculty TU Delft'

1998 / XII + 156 pages / ISBN 90-407-1714-1 


\section{Series 05: Aerospace Structures and Computional Mechanics}

01. A.J. van Eekelen, 'Review and Selection of Methods for Structural Reliability Analysis' 1997 / XIV + 50 pages / ISBN 90-407-1583-1

02. M.E. Heerschap, 'User's Manual for the Computer Program Cufus. Quick Design Procedure for a CUt-out in a FUSelage version 1.0' 1997 / VIII + 144 pages / ISBN 90-407-1584-X

03. C. Wohlever, 'A Preliminary Evaluation of the B2000 Nonlinear Shell Element Q8N.SM'

1998 / IV + 44 pages / ISBN 90-407-1585-8

04. L. Gunawan, 'Imperfections Measurements of a Perfect Shell with Specially Designed Equipment (UNIVIMP)

1998 / VIII + 52 pages / ISBN 90-407-1586-6

\section{Series 07: Aerospace Materials}

01. A. Vašek / J. Schijve, 'Residual Strenght of Cracked 7075 T6 Al-alloy Sheets under High Loading Rates' 1997 / VI + 70 pages / ISBN 90-407-1587-4

02. I. Kunes, 'FEM Modelling of Elastoplastic Stress and Strain Field in Centre-cracked Plate'

1997 / IV + 32 pages / ISBN 90-407-1588-2

03. K. Verolme, 'The Initial Buckling Behavior of Flat and Curved Fiber Metal Laminate Panels'

1998 / VIII + 60 pages / ISBN 90-407-1589-0

04. P.W.C. Provó Kluit, 'A New Method of Impregnating PEI Sheets for the In-Situ Foaming of Sandwiches'

1998 / IV + 28 pages / ISBN 90-407-1590-4

05. A. Vlot / T. Soerjanto / I. Yeri / J.A. Schelling, 'Residual Thermal Stresses around Bonded Fibre Metal Laminate Repair Patches on an Aircraft Fuselage'

1998 / IV + 24 pages / ISBN 90-407-1591-2

06. A. Vlot, 'High Strain Rate Tests on Fibre Metal Laminates'

1998 / IV + 44 pages / ISBN 90-407-1592-0

07. S. Fawaz, Application of the Virtual Crack Closure Technique to Calculate Stress Intensity Factors for Through Cracks with an Oblique Elliptical Crack Front'

1998 / VIII + 56 pages / ISBN 90-407-1593-9

08. J. Schijve, 'Fatigue Specimens for Sheet and Plate Material' 1998 / VI + 18 pages / ISBN 90-407-1594-7

09. J. Schijve, 'The Significance of Fractography for Investigations of Fatigue Crack Growth under Variable-Amplitude Loading'

1998 / IV + 34 pages / ISBN 90-407-1716-8 
10. M.J.L. van Tooren / Z.C. Roza, 'Finite Difference Methods for Stress Analysis of Adhesive Bonded Joints. The Design of a MATLAB Adhesive Toolbox'

1998 / VIII + 94 pages / ISBN 90-407-1717-6

\section{Series 08: Astrodynamics and Satellite Systems}

01. E. Mooij, 'The Motion of a Vehicle in a Planetary Atmosphere' 1997 / XVI + 156 pages / ISBN 90-407-1595-5

02. G.A. Bartels, 'GPS-Antenna Phase Center Measurements Performed in an Anechoic Chamber' 1997 / X + 70 pages / ISBN 90-407-1596-3

03. E. Mooij, 'Linear Quadratic Regulator Design for an Unpowered, Winged Re-entry Vehicle'

1998 / X + 154 pages / ISBN 90-407-1597-1 
